\title{
Developing Land and Structure Price Indices for Ottawa Condominium Apartments
}

\author{
Kate Burnett-Isaacs ${ }^{1}$, Ning Huang ${ }^{1}$, and W. Erwin Diewert ${ }^{2}$
}

\begin{abstract}
Measuring the service flow and the stock value of condominium apartments in Canada and decomposing these values into constant quality price and quantity components is important for many purposes. In addition, the System of National Accounts requires that these service flows and stock values for condos be decomposed into constant quality land and structure components. In Canada and most other countries, such a land and structure decomposition of condominium apartment sale prices does not currently exist. In this article, we provide such a decomposition of condominium apartment sales in Ottawa for the period 1996-2009. Specific attention is paid to the roles of communal land and structure space on condominium apartment unit selling prices. Key findings include methods to allocate land and building space to a single condominium unit, identifying the characteristics that best explain condominium prices, and developing an average depreciation rate for condos for the 14-year time period.
\end{abstract}

Key words: Condominium apartment price indices; land and structure price indices; hedonic regressions; net depreciation rates; system of national accounts.

\section{Introduction}

Over the last 15 years, the condominium apartment sector has been a growing component of the Canadian residential property market (Read-Hobman 2015). To accurately measure the economic activity in this sector, Statistics Canada is developing a New Condominium Apartment Price Index (NCAPI) and a Resale Residential Property Price Index for condominium apartments (RRPPI Condo). The use of the NCAPI and RRPPI Condo in statistical programs, for example as a deflator in various components of Gross Domestic Product and as an input into the Consumer Price Index, requires price indices for the total (land and structure components), as well as separate price index series for land and structures. Data on separate land and structure values are difficult to come by, resulting in a knowledge gap in condominium apartment information that the NCAPI and RRPPI Condo currently cannot fill.

\footnotetext{
${ }^{1}$ Producer Prices Division, Statistics Canada, Ottawa, Canada, K1A 0T6. Emails: kate.burnettisaacs@canada.ca and ning.huang2@canada.ca

${ }^{2}$ School of Economics, University of British Columbia, Vancouver B.C., Canada, V6T 1Z1. Email: erwin.diewert@ubc.ca.

Acknowledgments: The authors thank Heidi Ertl, Mary Beth Garneau, Gaétan Garneau and Clément Yélou at Statistics Canada and Price Measurement Advisory Committee members Jan de Haan, François Des Rosiers, Pierre Duguay, John Mallon and Mick Silver for their helpful discussions and comments. The authors also thank Amy Jiang, Simon Trottier and Ross Beck-MacNeil for their technical help on the data treatment. The views expressed in this article are solely those of the authors and do not necessarily reflect those of Statistics Canada. The last author gratefully acknowledges the financial support of the SSHRC of Canada and the Australian Research Council (LP0884095, DP150100830).
} 
In order to decompose a condominium apartment unit price into separate land and structure components, this article uses the Builder's Model developed by Diewert and Shimizu (2016). This hedonic model suggests that the value of a condominium unit is equal to the sum of the value of its land and structure components, where each component is impacted by different characteristics and factors. As proposed by Davis and Palumbo (2008), the structure component can be viewed as the current depreciated replacement cost to build the structure. The land component measures the impact that location and neighbourhood amenities, in addition to land size, have on the total price of a condominium apartment unit. The Builder's Model used in the article starts with finding the determinants of land prices, which are estimated as a "residual" of the total value of the property minus the structure component. Using the residual as an estimate for land value is crucial for choosing the factors affecting the land prices.

This study is an application of the work first developed by Diewert and Shimizu (2016), where we tackle the challenge of allocating communal land to a single condominium unit. This article demonstrates that their basic framework can be applied in another city's data sets, in this case Ottawa, Canada. We extend their work by better accounting for the existence of communal space in the building. The challenge here is that individual condominium units share communal structural space with the rest of the building. These communal building areas include lobbies, hallways, party rooms, gyms, pools, parking lots, etc. The cost of these amenities need to be allocated to the individual property units and incorporated into the Builder's Model. In addition, we test many characteristics in our Builder's Model that are common across countries, as well as some that are unique to Ottawa. This process verifies that the characteristics chosen by Diewert and Shimizu (2016) are the most important factors affecting land and structure condo prices. This is a very useful result for other statistical agencies in that it is not necessary to collect a large number of condo characteristics in order to obtain useful overall condo price indices and useful sub-indices for the land and structure components. Lastly, we show that our hedonic regressions can generate useful estimates of structure (net) depreciation rates for wear and tear depreciation of the structure.

In this study, we focus on the Ottawa high-rise condominium apartment market from 1996 to 2009. The article is broken down in the following manner: Section 2 explains the data used in this study; Section 3 introduces the Builder's Model and how it must be adapted to incorporate land and communal building space for condominium apartments; Section 4 focuses on finding the main determinants of land prices; Section 5 introduces various structural variables to the Builder's Model; Section 6 explains the land, structure and total property index series derived from our proposed hedonic model and Section 7 concludes.

\section{Data}

The source of data for this study is a combination of a residential property price research data set, a City of Ottawa building characteristics data set and some internet data sources. This research data set was developed for new and resale condominium apartment units for the 55 quarters from Q1 1996 to Q3 2009 based on the data availability. The term condominium apartment is defined by Statistics Canada's National Household Survey as a 
private residential complex in which dwellings are owned individually, while land and common elements are held in joint ownership with others. When we define a condominium apartment in this article, it does not include single-family homes or row houses that have condominium type ownership. More specifically, we focus on high-rise condos, which are defined as those condo buildings with five or more floors. This threshold was chosen because buildings with four or less floors are built similarly to single-family houses, with higher wood content than high-rise buildings that are built with more glass and concrete materials. The data set contains unit characteristic variables such as number of bedrooms and bathrooms, the type of heating fuel, floor covering, the story that the unit is on and unit square footage; land characteristics such as location of the condominium building described by the Forward Sortation Area (FSA), land size and excess land; and building structure characteristics include the building size, building height, unit height, and the total number of units in building.

Outlier detection was conducted for the main variables unit living area, selling price, bedroom, bathrooms, and age due to misreporting and unique units. To effectively detect outliers, we examined the histograms, summary statistics and detailed percentiles of living area, bedrooms and bathrooms. A simple cut-off technique was applied to remove the extreme values. For instance, the units with either top or bottom $1 \%$ living areas are removed from the sample; and the maximum values for bedrooms and bathrooms are trimmed off. The age restriction of 50 years was chosen because buildings older than this age will most likely have gone through a major renovation. Since we use age of the building to estimate depreciation, including buildings with major renovations would not provide accurate results. The selling prices were trimmed off unsymmetrically due to the fact that the distribution of selling prices are positive skewed. Different cut-off values were tested to determine how sensitive the final indices were to the choice of cut-off values with the help of pooled time dummy hedonic model. The final data set includes observations with the following characteristics:

- Living area between 300 and 1500 square feet (sqft),

- Selling price between bottom $1 \%$ and top $5 \%$ by year of sale,

- One to four bedrooms,

- One to three bathrooms, and

- Age $<50$ years.

Descriptive statistics for sales price by year is outlined in Table 1 and the main characteristic variables that will be used in our analysis are listed in Table 2 . It can be seen that, even after range trimming, there is still a great deal of variation in the explanatory variables such as selling prices, total residential building area and the lot size of the condo buildings.

\section{The Builder's Model for Condominium Apartments}

The Builder's Model is based on the expected cost of building a property, either a single family home or a condominium apartment unit. This model suggests that the selling price of a property that has a newly built structure on it is driven by the cost of producing said property. Thus, the hedonic form of the Builder's Model states that property price is equal 


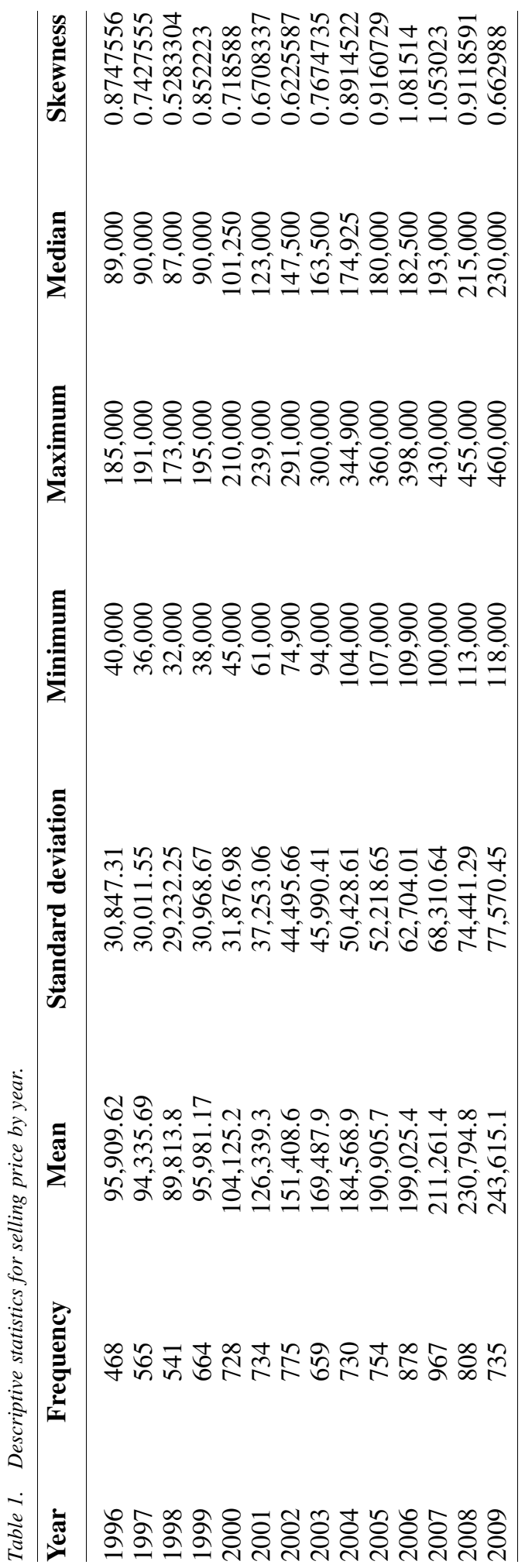




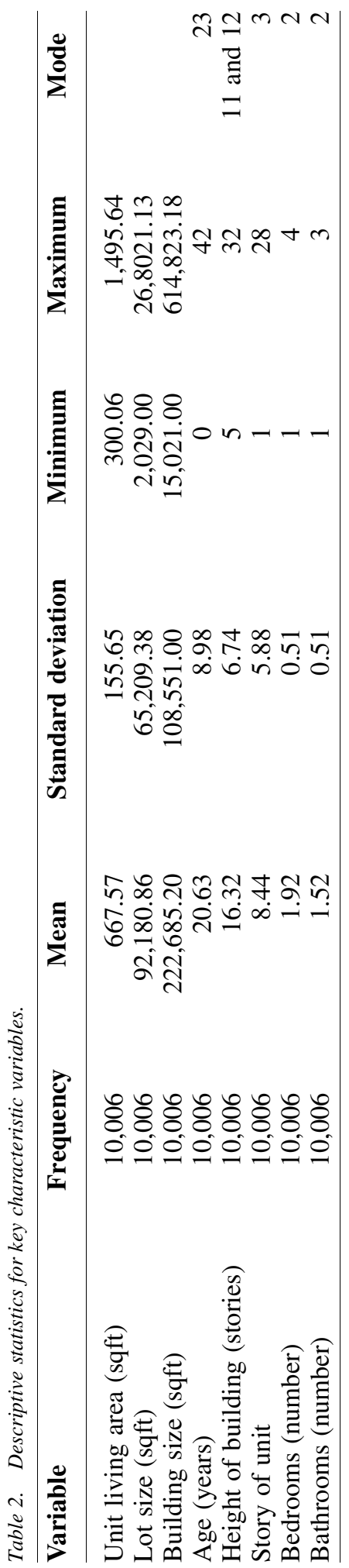


to the quality-adjusted cost of land per square foot $\left(\alpha_{t}\right)$ times the square footage of land $\left(T L_{t n}\right)$ plus the quality adjusted structure cost per square foot $\left(\beta_{t}\right)$ times the square footage of the structure $\left(S_{t n}\right)$ for $\mathrm{n}=1, \ldots N_{t}$, where $\mathrm{N}$ is the total number of observations, for a given time period $(t)$. The Builder's Model can be approximated by the following hedonic regression model, estimated using maximum likelihood estimation, with an error term $\left(\varepsilon_{t n}\right)$ that is assumed to be normally distributed with a mean of zero and a constant variance:

$$
P_{t n}=\alpha_{t} T L_{t n}+\beta_{t} S_{t n}+\varepsilon_{t n} ; \quad \mathrm{t}=1, \ldots, 55 ; \quad \mathrm{n}=1, \ldots, N_{t}
$$

The above model applies to new properties. A constant term is not included because of the assumption that if there is no land and no structure, the property has no value. To incorporate depreciation that occurs in older structures, which devalues the structure in the absence of renovations, the Builder's Model can use information on the age of the structure $\left(A_{t n}\right)$ in order to estimate a net geometric depreciation rate $\left(\delta_{t}\right)$ as the structure ages one period using the following model:

$$
P_{t n}=\alpha_{t} T L_{t n}+\beta_{t}\left(1-\delta_{t}\right)^{A_{t n}} S_{t n}+\varepsilon_{t n} ; \quad \mathrm{t}=1, \ldots, 55 ; \quad \mathrm{n}=1, \ldots, N_{t} .
$$

In trying to estimate Equation 2, as discussed in Handbook on Residential Property Price Indexes - RPPI Handbook (Diewert 2013), multicollinearity between the land and structure variables warrants the use of a construction cost index to proxy for the change in cost of building the structure. Multicollinearity occurs when two or more independent variables are correlated with each other. This can cause estimates to be unstable and difficult to interpret, with potentially incorrect signs or magnitudes. In this study, the price per square foot of a condominium is set equal to that from Statistics Canada's Apartment Building Construction Price Index (ABCPI). Using the ABCPI will allow our model to be consistent with the Canadian System of Macroeconomic Accounts estimates for the value of new construction. The use of this variable is based on the assumption that the movement of condominium apartment building costs approximates those for non-condominium apartment buildings. This assumption is based on the grounds that increasingly, rental apartment buildings are constructed with similar finishes as condos. This price per square foot is then indexed using the ABCPI for period t to get an estimated cost per square foot of structure space $\left(P S_{t}\right)$ for each quarter from Q1 1996 to Q3 2009. The resulting hedonic model is:

$$
P_{t n}=\alpha_{t} T L_{t n}+\beta P S_{t}\left(1-\delta_{t}\right)^{A_{t n}} S_{t n}+\varepsilon_{t n} ; \quad \mathrm{t}=1, \ldots, 55 ; \quad \mathrm{n}=1, \ldots, N_{t} .
$$

where $\beta$ coefficient now represents a general quality adjustment factor to the structure area and is constant over time. To apply the Builder's Model to condominium apartment units, we need to make additional considerations that would not be found in the Model for, say, single-family homes. The main considerations are how to address the roles of communal land and structure space on the selling price of a condominium apartment unit.

\subsection{Allocating the Unit's Land Share: Method 1}

In our data set, the variable for unit area is used to estimate the structure component for the unit only. However, land size is given for the whole building and not the single unit. 
Therefore, land size must be allocated appropriately to a single condo unit. The preliminary assumption is that each unit in the building equally enjoys the whole land area, therefore the land should be divided equally by all units in the building $\left(T U_{t n}\right)$ :

$$
L_{t n}=\left(\frac{1}{T U_{n}}\right) T L_{t n} ; \quad \mathrm{t}=1, \ldots, 55 ; \mathrm{n}=1, \ldots, N_{t} .
$$

In Section 4, we explore the alternative land imputation methods of allocated land proportional to the size of the unit and a weighted average of the equal distribution and size distribution methods.

\subsection{Allocating the Unit's Share of Communal Space}

A unique feature of condominium apartments, versus other building structures such as single-family homes, is that a single unit shares communal space with other units in the same building. This space and the amenities in it are accounted for, in addition to such sources of revenue as condo fees, in the selling price of the unit. However, when using the Builder's Model, the floor space of the condominium unit only covers the area of the privately owned space.

Explicit values of communal space are difficult to obtain and are often not reported in databases such as listing services, land registries or property assessment. Therefore, we need to estimate the proportion of the building space that is communal by other means. Consultations were conducted with the construction industry and an estimate for communal space was calculated using the apartment building specifications from the 2004 model used in the ABCPI. This model is representative of a building that can be built anywhere in Canada. From these two sources, it was determined that about $20-30 \%$ of the total floor space of the building is allocated to communal areas. We tested the sensitivity of this assumption and found that there was very little difference in the estimates of the Builder's Model using 20, 25 or 30\% values for communal space. Appendix 1 (Subsection 8.1 ) illustrates the result of using 20,25 and 30\% communal space on model 22 . Therefore, the hedonic models that follow will use an estimate for communal space of $25 \%$ of the total building area.

The floor area of the unit represents privately owned structure space. To capture all of the structural space allocated to a condominium unit, including communal space, the privately owned space in our model must be blown up by a factor that represents communal space. Since we are using the estimate of $25 \%$ of the building as communal space, $75 \%$ of the building is private space and so can be estimated by the unit floor space. To include that extra $25 \%$ of communal space in our model, structural space is estimated by

$$
(1 / 0.75) S_{m} \text { or }(1.33) S_{m}
$$

The amenities contained in this $25 \%$ communal space can differ between buildings and could be a factor affecting the price of a condominium unit. Tests were conducted to determine the impact that indoor and outdoor parking, fitness facilities, party rooms and indoor pools had on the price of a condominium unit. Since these communal amenities were shown to have a marginal impact on property values using the Builder's Model, and the results of regressions using communal amenities are not included in this study. In this 
study, a small impact is defined as improving the regression's Log Likelihood value by a small amount relative to the increase in the number of parameters.

\subsection{A Preliminary Builder's Model}

In order to get initial land value estimates, which will be discussed in Section 4, the depreciation rate was set equal to $2 \%$. This is the estimate used by the Canadian System of Macroeconomic Accounts and productivity analysis at Statistics Canada for all residential housing depreciation rates. Including the unit's share of land $\left(L_{t n}\right.$ defined by Equation (4)), the communal space blow-up factor (1.33), the price per square foot of structural floor space $\left(P S_{t}\right)$ and the exogenous annual depreciation rate $(0.02)$, the model defined by Equation (2) becomes the following model:

$$
P_{t n}=\alpha_{t} T L_{t n}+(1.33) \beta P S_{t}(1-0.02)^{A_{t n}} S_{t n}+\varepsilon_{t n} ; \mathrm{t}=1, \ldots, 55 ; \mathrm{n}=1, \ldots, N_{t} .
$$

The $\mathrm{R}^{2}$ value for this model turned out to be 0.6774 , which indicated that there was room for improvement in the model. However, the results for this model were not plausible. Most $\alpha t$ values, which are the estimates for average price of land per square foot, were negative. Negative prices cannot exist in this context. Also, the $\beta$ coefficient estimate, representing a general structure quality adjustment factor, was 5.02528 (tstat $=330.25$ ). Our assumption is that the model can account for almost all quality adjustment to the structure implying that $\beta$ should be close to a value of 1 . Thus, the very large estimate for $\beta$ has led to $\alpha_{t}$ estimates which are too small to be credible, as demonstrated in Appendix 2 (Subsection 8.2).

\section{The Determinants of Condominium Land Prices}

To improve the results of the model defined by Equation (5), we set $\beta$ equal to 1 which allowed us to focus on finding the main determinants of land prices. To do this, we temporarily took imputed land value to be the dependent variable of our hedonic model. We derive an estimate for imputed land value for property $\mathrm{n}$ in period $\mathrm{t},\left(L V_{t n}\right)$, by subtracting our imputed structure value $\left(S V_{t n}\right)$ from the total property-selling price $\left(P_{t n}\right)$ :

$$
L V_{t n}=P_{t n}-S V_{t n} ; \quad \mathrm{t}=1, \ldots, 55 ; \mathrm{n}=1, \ldots, N_{t} .
$$

Our imputed structure value is approximated by:

$$
S V_{t n}=(1.33) P S_{t}(1-0.02)^{A_{t n}} S_{t n} ; \quad \mathrm{t}=1, \ldots, 55 ; \mathrm{n}=1, \ldots, N_{t}
$$

The above estimates for land value were then used as the dependent variable for the models that are described in this section. The baseline model we will use to begin our analysis is that land value in period $\mathrm{t}$ can be modeled by the price of land per square foot $\left(\alpha_{t}\right)$ multiplied by the equally distributed land area defined by Equation (4) above, $\left(L_{t n}\right)$ :

$$
L V_{t n}=\alpha t L_{t n}+\varepsilon_{t n} ; \quad \mathrm{t}=1, \ldots, 55 ; \mathrm{n}=1, \ldots, N_{t}
$$

This model gave us a starting point to assess the impact of additional land characteristics on the goodness of fit of the subsequent models. The very simple model defined by Model (8) had an R square value of $(0.673$ and a log likelihood value (LL) of $(127,824)$. 
This negative $\mathrm{R}$ square value is a result of not having a constant term in Model (8). Given the nonlinear nature of this and subsequent models, goodness of fit will be determined by the combined improvement in the LL and the R-square values.

\subsection{Introducing Postal Code Dummy Variables}

The results of Model (8) clearly suggest that there needed to be an improvement in how we modeled land prices. The price of any property is heavily impacted by location. To capture this relationship, we use Forward Sortation Area dummy variables $\left(F S A_{t n, i}\right)$ in our hedonic model. A forward sortation area (FSA) is a geographic unit based on the first three characters in a Canadian postal code. These 22 dummy variables are defined as:

$$
\begin{aligned}
F S A_{t n, i} & =1 \text { if observation } \mathrm{n} \text { in period } \mathrm{t} \text { is in Forward Sortation Area } \mathrm{i} \\
& =0 \text { otherwise. }
\end{aligned}
$$

By adding the Forward Sortation Area dummy variables to Model (8) we can account for how the land prices change based on the location of the condominium:

$$
L V_{t n}=\alpha_{t}\left(\sum_{i=1}^{22} \theta_{i} F S A_{t n, i}\right) L_{t n}+\varepsilon_{t n} ; \quad \mathrm{t}=1, \ldots, 55 ; \quad \mathrm{n}=1, \ldots, N_{t}
$$

where the land size by unit $\left(L_{t n}\right)$ is defined as in Equation (4). The $55 \alpha_{t}$ parameters and 22 $\theta_{i}$ parameters cannot all be identified. Therefore, we normalized $\alpha_{1}=1$. With $\alpha_{1}=1$, the value of all other $\alpha_{t}$ estimates represent the percentage change in land value due to the change in time from period 1 to period $t$. This is the definition of a price index and so we can use the parameter estimates of land price to create our land price index. The R-square for this model was 0.0984 and the LL was $(124,732$, which was a large 3,092 improvement from Model (8), validating our assumption that location has a significant impact on the land prices in Ottawa.

\subsection{Alternative Land Value Distribution Methods}

Up to this point, our models assumed that land was equally distributed to each condominium apartment unit. However, land could also be allocated to a single unit proportionally to the floor size of the unit or to a combination of equal and proportional allocation.

Land can be allocated to a single unit proportionally to its size compared to the rest of the building. Like in the case of condo fees, where larger units pay higher fees and thus contribute more to funding communal spaces, the logic in this assumption is that the larger units should have a larger share of the land. Proportional land size $\left(L_{t n}\right)$ is defined as:

$$
L_{t n}^{*}=\left(\frac{S_{t n}}{T S_{t n}}\right) T L_{t n} ; \quad \mathrm{t}=1, \ldots, 55 ; \quad \mathrm{n}=1, \ldots, N_{t}
$$


Replacing the $L_{t n}$ variable in equations (10) by the proportional land variable $L_{t n}^{*}$ defined in (11), our model becomes:

$$
\begin{aligned}
L V_{t n} & =\alpha t\left(\sum_{i=1}^{22} \theta_{i} F S A_{t n, i}\right)\left(\frac{S_{t n}}{T S_{t n}}\right) T L_{t n}+\varepsilon_{t n} ; \quad \mathrm{t}=1, \ldots, 55 \\
\mathrm{n} & =1, \ldots, N_{t} .
\end{aligned}
$$

However, the R-square and LL values from this model, -0.0956 and $-125,172$ respectively, were worse than those of Model (10).

Given that Model (12) provides worse results than Model (10), we need to find a different method to determine the land share of a single unit. An alternative method is to distribute the total land among the units in the building by a weighted average of the equal and the proportional allocation:

$$
L_{t n}^{* *}=\left[\rho\left(\frac{S_{t n}}{T S_{t n}}\right)+(1-\rho)\left(\frac{1}{T U_{t n}}\right)\right] T L_{t n} ; \quad \mathrm{t}=1, \ldots, 55 ; \quad \mathrm{n}=1, \ldots, N_{t}
$$

The $\rho$ coefficient is estimated in Model (14) below:

$$
\begin{aligned}
& L V_{t n}=\alpha_{t}\left(\sum_{i=1}^{22} \theta_{i} F S A_{t n, i}\right)\left[\rho\left(\frac{S_{t n}}{T S_{t n}}\right)+(1-\rho)\left(\frac{1}{T U_{t n}}\right)\right] T L_{t n}+\varepsilon_{t n} \\
& \mathrm{t}=1, \ldots, 55 ; \quad \mathrm{n}=1, \ldots, N_{t}
\end{aligned}
$$

The estimate of $\hat{\rho}$ was 0.24021 (t stat $=11.42$ ), therefore placing a higher weight towards equally distributing the land to a single unit. This makes sense given the poor performance of proportionally distributing land alone, as was found in Model (12).

The R-square of Model (14) was 0.1025 and the LL was $-124,178$, which is an improvement of 994 on Model (12) and an improvement of 554 on Model (10). Therefore, subsequent models of land value and total property price will use this weighted land distribution method. The intuition for including the weighted average is that the more units in a building, the greater the heterogeneity in size of the units within the building, and so the greater the impact a unit of a larger size, or larger proportional size, has on price.

\subsection{Introducing the Height of the Unit}

Our expectation is that a unit on a higher floor will have a better view than those on lower floors. The view can be thought as the vertical dimension of land. Therefore, the floor the unit is on, or the height of the unit $\left(H_{t n}\right)$, impacts the price of land for a condominium unit. The variable $H_{t n}$ was added to Model (14) as a continuous variable because it represented the response of the unit's price to a change in height of the unit in a more parsimonious way than using height dummy variables. Thus, we added $\left(1+\gamma\left(H_{t n}-1\right)\right)$ to Model (14) 
and obtain Model (15):

$$
\begin{aligned}
& L V_{t n}=\alpha_{t}\left(\sum_{i=1}^{22} \theta_{i} F S A_{t n, i}\right)\left(1+\gamma\left(H_{t n}-1\right)\right)\left[\rho\left(\frac{S_{t n}}{T S_{t n}}\right)+(1-\rho)\left(\frac{1}{T U_{t n}}\right)\right] T L_{t n}+\varepsilon_{t n} \\
& \mathrm{t}=1, \ldots, 55 ; \quad \mathrm{n}=1, \ldots, N_{t} .
\end{aligned}
$$

Even though $H_{t n}$ is a continuous variable, we still normalize the impact that the height of the unit has over the lowest floor observed in our data, in this case the first story. The predicted value of land price will not be affected by those observations corresponding to a unit sold on the first floor. For any unit on a floor above the first floor, the land price will increase by $\gamma$ for each story. Our estimate for $\hat{\gamma}$ was 0.04121 (t stat $=29.22$ ). Therefore, the predicted land price of a condominium unit increased by $4.12 \%$ for every story above the first floor. The R-square of this model is 0.1893 and the LL was $-123,671$, an increase of 507 over Model (14).

\subsection{Introducing the Number of Units in the Building}

In order to build a condominium apartment building, land needs to be zoned for the type and size of building. A building with more units will cost more in zoning fees and builders will pass these extra costs on to consumers. To test the extent to which an extra unit impacts the sale price of a condominium unit, we introduce the total number of units $\left(T U_{t n}\right)$ into Model (15) in a similar fashion to the height of the unit $\left(H_{t n}\right)$ as a continuous variable. Again, we normalized the impact that an extra unit will have above the minimum number of units found in a building in our data set. In this case, that minimum number of units is nine. We updated Model (15) with multiplicative factor $\left(1+\omega\left(T u_{t n}-9\right)\right)$ where $\omega$ represents the percentage change in land value due to an increase of one extra unit in the total number of units found in a building. If the building has nine units in it, its land value will be unaffected.

Our new hedonic model is as follows:

$$
\begin{gathered}
L V_{t n}=\alpha_{t}\left(\sum_{i=1}^{22} \theta_{i} F S A_{t n, i}\right)\left(1+\gamma\left(H_{t n}-1\right)\right)\left(1+\omega\left(T U_{t n}-9\right)\right) \\
{\left[\rho\left(\frac{S_{t n}}{T S_{t n}}\right)+(1-\rho)\left(\frac{1}{T U_{t n}}\right)\right] T L_{t n}+\varepsilon_{t n}} \\
\mathrm{t}=1, \ldots, 55 ; \quad \mathrm{n}=1, \ldots, N_{t} .
\end{gathered}
$$

The R-square value of Model (16) was 0.2944 and the LL was $-122,980$, which is an increase of 691 over Model (15). The resulting estimate for $\hat{\omega}$ is 0.009432 ( $\mathrm{t}$ stat $=34.22$ ) indicating that one extra unit in the building will increase the value of land for a single condominium unit by $0.94 \%$.

\subsection{Introducing the Height of the Building}

Certain neighbourhoods are zoned for tall buildings, such as downtown areas. These buildings are generally more expensive, but to what extent is that because these buildings are tall or because they are in downtown? In Model (10) we accounted for location, so now 
we want to determine the impact building height has on land values. To measure this effect, we introduce four height of building dummy variables to Model (16) based on the quartiles of the total building height $\left(T H_{t n}\right)$ found in our data set. Group 1 is defined as containing observations for $T H_{t n}<11$ stories; group 2 contains observations where $11 \leq T H_{t n}<15$; group 3 contains observations where $15 \leq T H_{t n}<22$ and group 4 contains observations where $T H_{t n} \geq 22$. The quartile groupings were chosen to ensure that there were enough observations for all dummy variables. The total building height dummy variable is defined as:

$$
\begin{aligned}
T H_{t n, j} & =1 \text { if observation } \mathrm{n} \text { in period } \mathrm{t} \text { is in total building height group } \mathrm{j} ; \\
& =0 \text { otherwise. }
\end{aligned}
$$

It is important to note that the height of the building does not change over time. Since our observations are observed for a given time $t$, we include the time subscript in our variable definition. The hedonic model including the total height dummy variables is as follows:

$$
\begin{gathered}
L V_{t n}=\alpha_{t}\left(\sum_{i=1}^{22} \theta_{i} F S A_{t n, i}\right)\left(1+\gamma\left(H_{t n}-1\right)\right)\left(1+\omega\left(T U_{t n}-9\right)\right)\left(\sum_{j=1}^{4} \vartheta_{j} T H_{t n, j}\right) \\
\quad\left[\rho\left(\frac{S_{t n}}{T S_{t n}}\right)+(1-\rho)\left(\frac{1}{T U_{t n}}\right)\right] T L_{t n}+\varepsilon_{t n} \\
\mathrm{t}=1, \ldots, 55 ; \quad \mathrm{n}=1, \ldots, N_{t} .
\end{gathered}
$$

The four total building height parameters $\left(\vartheta_{j}\right)$, the 22 Forward Sortation Area dummy parameters $\left(\theta_{i}\right)$ and the 55 land price parameters in Model (18) cannot be all identified, therefore we apply the following normalizations on these parameters:

$$
\alpha_{1}=1 ; \vartheta_{1}=1
$$

The R-square value for Model (18) was 0.3594 and the LL was -122,498, an increase of 482 over the LL of Model (16). The estimated total building height parameters increase as the building height increases, suggesting that even accounting for location, building height increases land prices. Introducing height of the building after height of the unit also brings in the concept of relative height. A unit on the 10th floor of an 11-story building will have a different price than a unit on the 10th floor of a 20 -story building because of the different view that it would offer after controlling the location of the building. Taller buildings may add benefit to the view because they are taller than surrounding buildings or match the height of surrounding buildings.

\subsection{Introducing Excess Land}

The excess land surrounding a condominium building can incorporate many land characteristics that we cannot account for given our data. Excess land is measured as the total land plot area minus the building footprint (total building floor area divided by number of floors in the building). If a building has a large amount of excess land it could mean this excess property contains amenities such as outdoor parking, outdoor pools, 
parks and pathways. We do not have these amenity characteristic variables in our data set and so excess land can account for some of these extra land features. We created four excess land dummy variables $\left(E L_{t n, m}\right)$ based on the quartiles of excess land size found in our data: group 1 is made up of observations where $E L_{t n}<22,254$ square feet; group 2 contains observations where $22,254 \leq E L_{t n}<76,424$ square feet; group 3 contains observation where $76,424 \leq E L_{t n}<124,269$ and group 4 contains observations where $E L_{t n} \geq 124,269$. The quartile ranges were chosen to ensure that there were enough observations for each grouping of excess land. The excess land dummy variables are created as follows:

$$
\begin{aligned}
E L_{t n, m} & =1 \text { if observation } \mathrm{n} \text { in period } \mathrm{t} \text { is in excess land group } \mathrm{m} ; \\
& =0 \text { otherwise; }
\end{aligned}
$$

In addition to the normalizations imposed for Model (18), we set $\sigma_{l}=1$, so that all remaining parameters can be identified. We added these $E L_{t n, m}$ dummy variables to Model (18) to get the following model:

$$
\begin{gathered}
L V_{t n}=\alpha t\left(\sum_{i=1}^{22} \theta_{i} F S A_{t n, i}\right)\left(1+\gamma\left(H_{t n}-1\right)\right)\left(1+\omega\left(T U_{t n}-9\right)\right)\left(\sum_{j=1}^{4} \vartheta_{j} T H_{t n, j}\right) \\
\left(\sum_{m=1}^{4} \sigma_{m} E L_{t n, m}\right)\left[\rho\left(\frac{S_{t n}}{T S_{t n}}\right)+(1-\rho)\left(\frac{1}{T U_{t n}}\right)\right] T L_{t n}+\varepsilon_{t n} \\
\mathrm{t}=1, \ldots, 55 ; \mathrm{n}=1, \ldots, N_{t} .
\end{gathered}
$$

where $\alpha_{1}=1 ; \vartheta_{1}=1$; and $\sigma_{1}=1$.

The R-square value for Model (21) was 0.6199 and the LL was $(119,898$, which is a 2,600 improvement over the LL of Model (18). Even though excess land has a significant impact, the results are not what we originally expected. Due to the amenities and potential view that more excess land could offer a condominium unit, we assumed that more excess land would increase the unit price of land. However, as one can see in Table 3, although the excess land is positively related to the price of land, the estimated $\hat{\sigma}_{m}$ decreased as the excess land gets bigger, which seems counterintuitive to our assumption. The same result was found in Diewert and Shimizu (2016). The significant increase in LL with the inclusion of excess land signifies that the presence of extra land is an important factor in determining the sales price of a condominium apartment. However, the decrease in the estimated $\hat{\sigma}_{m}$ suggests there might be decreasing returns to scale for excess land. Moreover, with further examination of the data, it could be seen that, generally speaking, condominium buildings with relatively small excess land are concentrated in the downtown core of Ottawa; while buildings with larger excess land are mainly located far away from the central area.

\subsection{Estimates for the Determinants of Land Value}

Table 3 displays the estimated coefficients and T statistics for key determents of land value from Model (14) to (21), where $\hat{\gamma}$ is the estimate for change in land value of a unit due to an increase in the floor that unit is on, $\hat{\omega}$ is the estimate for the change in land value for a unit 


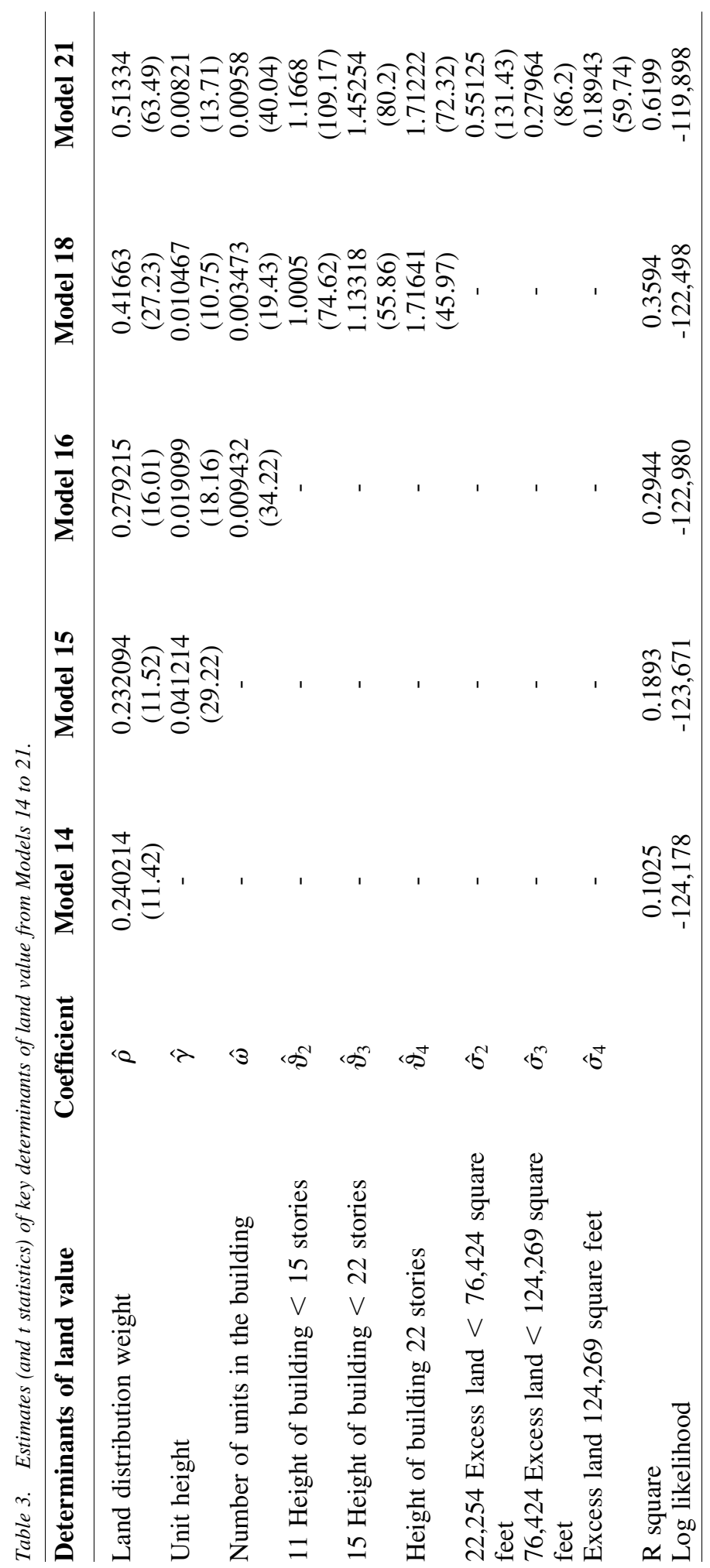


due to an extra unit in the building, $\hat{\vartheta}_{j}$ are the parameter estimates for the total building height dummy variables, $\hat{\sigma}_{m}$ are the parameter estimates for the excess land dummy variables and lastly, $\hat{\rho}$ is the land distribution weight estimate. Appendix 3 (Subsection 8.3) displays the final estimates for Model (21), where $\hat{\theta}_{i}$ are the parameter estimates for the Forward Sortation Area dummy variables, and $\hat{\alpha}_{t}$ are the parameter estimates for land value for a condominium unit in period $t$.

With the final determinants of land value all included in Model (21), our parameters previously estimated have changed. The main parameter change to note is the land imputation weight $(\hat{\rho})$ which grew from 0.240 in Model (14) to 0.513 in Model (21). This means that in Model (21) the proportional to size land imputation method gets about the same weight as the equal share land imputation method. We also see that height of the unit $(\hat{\gamma})$ now has a lesser impact on land value at $0.82 \%$ per additional floor. Certain trends continue in Model (21). The parameter estimates for building height $\left(\hat{\vartheta}_{j}\right)$ increased as the height increases. We also still observe that the excess land coefficient estimates $\left(\hat{\sigma}_{m}\right)$ decreased with the size of excess land. Though this variable significantly improves our model, as was suggested by the 2,600 increase in LL with the inclusion of this variable, the resulting estimates suggest that extra land might not be a priority for consumers looking to purchase condominium apartment units.

\section{Quality Adjustment Variables for the Structure Component of Condo Value}

Now that we have determined the main characteristics that contribute to land prices, we can use these variables in a Builder's Model that includes both land and structure components. Thus in the model defined by Equation (22), the net geometric depreciation rate $(\delta)$ is estimated (instead of being set equal to $2 \%$ ) and where the dependent variable is now the condominium property price (instead of the imputed land value):

$$
\begin{aligned}
P_{t n}=\alpha t & \left(\sum_{i=1}^{22} \theta_{i} F S A_{t n, i}\right)\left(1+\gamma\left(H_{t n}-1\right)\right)\left(1+\omega\left(T U_{t n}-9\right)\right)\left(\sum_{j=1}^{4} \vartheta_{j} T H_{t n, j}\right) \\
& \left(\sum_{m=1}^{4} \sigma_{m} E L_{t n, m}\right)\left[\rho\left(\frac{S_{t n}}{T S_{t n}}\right)+(1-\rho)\left(\frac{1}{T U_{t n}}\right)\right] T L_{t n}+(1.33) P S_{t} \\
& (1-\delta)^{A_{t n}} S_{t n}+\varepsilon_{t n} ; \quad \mathrm{t}=1, \ldots, 55 ; \mathrm{n}=1, \ldots, N_{t} .
\end{aligned}
$$

The R-square value of Model (22) was 0.6975 and the LL was $-119,869$. The estimate for the depreciation rate $(\hat{\delta})$ was $0.010636(\mathrm{t}$ stat $=10.41)$, which is much lower than expected. Therefore, we need to consider structural quality adjustment factors, such as the number of bedrooms and the number of bathrooms, in our Builder's Model before we adopt this lower net depreciation rate.

\subsection{Introducing the Number of Bedrooms}

Even after accounting for unit size, the number of bedrooms in a condominium unit can impact its selling price. The condominium units found in our data have between one to four bedrooms. We group our observations based the number of bedrooms found in the unit: group 1 contains observations with one bedroom; group 2 observations have two 
bedrooms and group 3 observations have three or four bedrooms. Three and four bedrooms were grouped together due to the small sample size of units with four bedrooms. We introduce a bedroom dummy variables $\left(B D_{t n, k}\right)$ into Model (22) based on the following definitions:

$$
\begin{aligned}
B D_{t n, k} & =1 \text { if observation } \mathrm{n} \text { in period } \mathrm{t} \text { is in bedroom group } \mathrm{k} \\
& =0 \text { otherwise. }
\end{aligned}
$$

The hedonic model accounting for the impact of bedrooms on selling price is as follows:

$$
\begin{aligned}
P_{t n}=\alpha t( & \left.\sum_{i=1}^{22} \theta_{i} F S A_{t n, i}\right)\left(1+\gamma\left(H_{t n}-1\right)\right)\left(1+\omega\left(T U_{t n}-9\right)\right)\left(\sum_{j=1}^{4} \vartheta_{j} T H_{t n, j}\right) \\
& \left(\sum_{m=1}^{4} \sigma_{m} E L_{t n, m}\right)\left[\rho\left(\frac{S_{t n}}{T S_{t n}}\right)+(1-\rho)\left(\frac{1}{T U_{t n}}\right)\right] T L_{t n}+(1.33) P S_{t} \\
& (1-\delta)^{A_{t n}}\left(\sum_{k=1}^{3} \tau_{k} B D_{t n, k}\right) S_{t n}+\varepsilon_{t n} ; \quad \mathrm{t}=1, \ldots, 55 ; \quad \mathrm{n}=1, \ldots, N_{t} .
\end{aligned}
$$
(24):

We apply the following normalization parameters to the model defined by Equation

$$
\alpha_{1}=1 ; \vartheta_{1}=1 ; \sigma_{1}=1 ; \text { and } \tau_{1}=1
$$

The R-square value for Model (24) was 0.7764 and the LL was -118,364, which is a 1,505 increase in the LL from Model (22). This large increase in LL indicates that the number of bedrooms significantly impacts the selling price of a condominium unit. The coefficient estimates increased with the number of bedrooms in the unit, signifying that more bedrooms increased the sale price of a condominium apartment unit.

\subsection{Introducing the Number of Bathrooms}

Bathrooms are key features in any residential property and condominium apartment units are no exception. To test the exact impact that bathrooms have on the selling price of condominium units, we introduce a number of bathroom dummy variables as structure quality adjustment variables. The condominium units found in our data have between one and three bathrooms. We group our observations based on the number of bathrooms found in the condominium unit: group 1 observations have one bathroom; group 2 observations have two bathrooms, and group 3 observations have three bathrooms. We introduce bathroom dummy variables $\left(B T_{t n, c}\right)$ into Model (24) based on the following definitions:

$$
\begin{aligned}
B T_{t n, c} & =1 \text { if observation } \mathrm{n} \text { in period } \mathrm{t} \text { is in bathroom group } \mathrm{c} \\
& =0 \text { otherwise. }
\end{aligned}
$$


The hedonic model including the number of bathrooms is as follows:

$$
\begin{aligned}
& P_{t n}=\alpha t\left(\sum_{i=1}^{22} \theta_{i} F S A_{t n, i}\right)\left(1+\gamma\left(H_{t n}-1\right)\right)\left(1+\omega\left(T U_{t n}-9\right)\right)\left(\sum_{j=1}^{4} \vartheta_{j} T H_{t n, j}\right) \\
&\left(\sum_{m=1}^{4} \sigma_{m} E L_{t n, m}\right)\left[\rho\left(\frac{S_{t n}}{T S_{t n}}\right)+(1-\rho)\left(\frac{1}{T U_{t n}}\right)\right] T L_{t n}+(1.33) P S_{t} \\
&(1-\delta)^{A_{t n}}\left(\sum_{k=1}^{3} \tau_{k} B D_{t n, k}\right)\left(\sum_{c=1}^{3} \varphi_{c} B T_{t n, c}\right) S_{t n}+\varepsilon_{t n} \\
& \mathrm{t}=1, \ldots, 55 ; \quad \mathrm{n}=1, \ldots, N_{t} .
\end{aligned}
$$

As in previous models, we need to apply normalization parameters to Model (27), in order to identify the remaining parameters. The normalizations are as follows:

$$
\alpha_{1}=1 ; \vartheta_{1}=1 ; \sigma_{1}=1 ; \tau_{1}=1 ; \text { and } \varphi_{1}=1
$$

The model defined by (27) had an R-square value of 0.7848 and a LL of $(118,172$, which is an increase in LL of 192 from Model (25). The positive and increasing values of $\hat{\varphi}_{2}$ and $\hat{\varphi}_{3}$, at 1.328436 (t-stat $\left.=77.88\right)$ and 1.478348 ( $\mathrm{t}$-stat $\left.=22.56\right)$ respectively, suggest that the more bathrooms found in a condominium unit, the higher it will sell for.

\subsection{Additional Structure Characteristics As Explanatory Variables}

Other structural characteristic variables were added to the model defined by Model (27) such as hardwood floors in the unit, natural gas in the unit, the number of appliances in the unit, on-suite bathrooms, dens, balconies, whether or not the unit was a new build and condo fees. Only balconies and the presence of natural gas in the unit significantly improved the model. Significant improvement of the model in this case refers to improving the model by at least 100 LL points. Though this is not a critical value when conducting a Log Likelihood test, this threshold was chosen because adding more variables to our hedonic non-linear model made it more difficult for the model to converge. Therefore, the threshold of 100 was chosen to balance convergence with variable choice. Both the balcony and natural gas variables are grouped into two categories: group 1 are for those observations that have the structural characteristic and group 2 are those observations that do not have the structural characteristic in question. To include balconies and natural gas into our Builder's Model we introduce a balcony $\left(B C_{t n, y}\right)$ and a natural gas $\left(N G_{t n, z}\right)$ dummy variable to Model (27) defined as:

$$
\begin{aligned}
B C_{t n, y} & =1 \text { if observation } \mathrm{n} \text { in period } \mathrm{t} \text { is in group } \mathrm{y} ; \\
& =0 \text { otherwise. } \\
N G_{t n, z} & =1 \text { if observation } \mathrm{n} \text { in period } \mathrm{t} \text { is in group } \mathrm{z} ; \\
& =0 \text { otherwise. }
\end{aligned} .
$$

Both variables were added individually and combined to Model (27). Adding balconies only to Model (27) resulted in an R-square value of 0.7972 and a LL $-117,876$, which is an improvement of 296 over the LL of Model (27). Adding natural gas to Model (27) resulted 
in an R-square value of 0.7961 and a LL of (117,903, an improvement of 269. Since both structural characteristics individually improved the model, we introduced balcony and natural gas dummy variables to Model (27) as shown in Model (31):

$$
\begin{aligned}
P_{t n}=\alpha t & \left(\sum_{i=1}^{22} \theta_{i} F S A_{t n, i}\right)\left(1+\gamma\left(H_{t n}-1\right)\right)\left(1+\omega\left(T U_{t n}-9\right)\right)\left(\sum_{j=1}^{4} \vartheta_{j} T H_{t n, j}\right) \\
& \left(\sum_{m=1}^{4} \sigma_{m} E L_{t n, m}\right)\left[\rho\left(\frac{S_{t n}}{T S_{t n}}\right)+(1-\rho)\left(\frac{1}{T U_{t n}}\right)\right] T L_{t n}+(1.33) P S_{t} \\
& (1-\delta)^{A_{t n}}\left(\sum_{k=1}^{3} \tau_{k} B D_{t n, k}\right) \\
& \left(\sum_{c=1}^{3} \varphi_{c} B T_{t n, c}\right)\left(\sum_{y=1}^{2} \pi_{y} B C_{t n, y}\right)\left(\sum_{z=1}^{2} \eta_{z} N G_{t n, z}\right) S_{t n}+\varepsilon_{t n} ; \\
& \mathrm{t}=1, \ldots, 55 ; \quad \mathrm{n}=1, \ldots, N_{t} .
\end{aligned}
$$

As in previous models, every parameter cannot be identified, so we applied the following normalization restrictions to Model (31):

$$
\alpha_{1}=1 ; \vartheta_{1}=1 ; \sigma_{1}=1 ; \tau_{1}=1 ; \varphi_{1}=1 ; \pi_{1}=1 ; \text { and } \eta_{1}=1 \text {. }
$$

Model (31) had an R-square value of 0.8052 and a LL - 117,677, which is an improvement in LL over Model (27) by 495. The coefficient estimates for the balcony and natural gas dummy variables are 1.247762 (t-stat $=137.27$ ) and 1.230578 (t-stat $=133.33$ ), respectively. These values are consistent with our expectations. Balconies can increase the price of a condominium unit because it provides additional living space, as well as an ideal "observation post" for enjoying the view. Furthermore, natural gas is considered to be an important and preferred means of heating homes in Ottawa and so its presence should increase the price of a condominium unit.

Table 4 lists the estimated structure coefficients for Models (22) to (31). These additional coefficients estimates include the net geometric depreciation rate $(\hat{\delta})$, the bedroom dummy variables $\left(\hat{\tau}_{k}\right)$, the bathroom dummy variables $\left(\hat{\varphi}_{c}\right)$, the balcony dummy variable $\left(\hat{\pi}_{2}\right)$ and the natural gas dummy variable $\left(\hat{\eta}_{2}\right)$. A full list of the estimates from Model (31) are found in Appendix 4 (Subsection 8.4).

From Model (31), we also got an estimate for the average net geometric depreciation rate $(\hat{\delta})$, which was 0.023508 (t stat $=46.04)$, for the entire Q1 1996 to Q3 2009 period. It is slightly higher than the estimate used by Statistics Canada's Canadian System of Macroeconomic Accounts for deflating residential construction activity and for conducting productivity analysis.

However, it should be kept in mind that our estimated geometric depreciation rate of $2.4 \%$ per year may be subject to some downward bias for two reasons:

1. Capital expenditures on maintaining and renovating the structure are not taken into account in our model, so that we are estimating a net of capital expenditures depreciation rate rather than a gross depreciation rate,

2. Our model does not take into account the premature demolition of condominium buildings; that is, we only observe sales of surviving structures. This could be a source of bias. This problem can be addressed if information on the age of buildings 


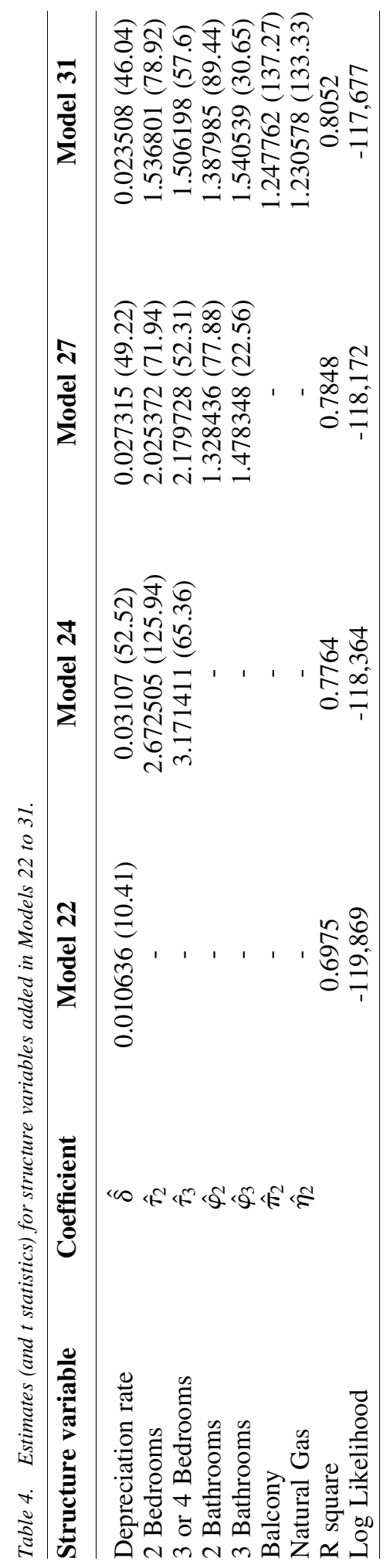


when they are demolished is available. Diewert and Shimizu (2017) has addressed this problem. For commercial structures in Tokyo, they found that the demolition depreciation added an additional $2 \%$ per year to their estimated net depreciation rate obtained using the Builder's Model.

When determining the important factors that contribute to land value or the total price of a property, it is important to note that, though the magnitude of the difference in loglikelihood values between models may vary, the choice of variables included in our model are not impacted by the order in which they are included in the model. To further assess the robustness of the choice of our property characteristics, we estimated our models over a range of time periods, specifically 1996-2003, 1996-2004, 1996-2005, 1996-2006, 1996-2007, 1996-2008, and 2003-2009. A sample of the results from the time periods of 1996 to 2003 and 1996 to 2008 are compared to Models 21 and 31 in Appendix 5 (Subsection 8.5). Our results were similar for the key determinants of land across all time periods (as shown in Table 9 in Appendix 5). When the full Builder's Model was assessed across all time periods, the estimates were similar and the same choices in characteristics remained the same. However, there was a notable difference in the value of $\hat{\rho}$, the land distribution weight estimate. In Model 21, there is a near 50-50 split between equal and proportional distribution of land to a condo unit. This is the case across all time periods tested. When we include the structure components to complete the Builder's Model, the land distribution weight greatly favours equal distribution of land. In Model 31, $\hat{\rho}$ has a value of $0.10284(\mathrm{t}$ stat $=6.12$ ) meaning that equal distribution of land has a roughly $90 \%$ weight. However, in the early time periods, $\hat{\rho}$ is negative, meaning that proportional distribution of land has a negative weight. In the later time periods, for example 1996 to 2008 or 2003 to 2009, $\hat{\rho}$ closely resembles the value we received in Model 31 of $10 \%$. The main conclusion to this analysis is that a robust Builder's Model can be estimated with only equal distribution of land to a condo unit.

\section{The Resulting Price Indices}

Now that we have estimates for land prices, we can use them to construct land, structure and total property price indices. The main goal of this article is to present a sound methodology to create separate land and structure price indices. These indices are quite unique in Canada, specifically there is no other land price index for the city of Ottawa to confront our results with. Therefore, we will be constructing a total property price index by aggregating the land and structure components developed in this article. This allows us to confront our results with more common methods of calculating price indices.

\subsection{Constructing Land, Structure and Total Condominium Sales Price Indices}

When we are modeling the value of land, $\left(\alpha_{t}\right.$ estimates represent the percentage change in land price due to the change in time from period 1 to period $t$, and we can use these estimates to create land price indices $\left(I L_{t}\right)$ as follows:

$$
I L_{t}=\alpha_{t} \times 100 ; \quad \mathrm{t}=1, \ldots, 55 .
$$


The structure price index is a normalization of the official Statistics Canada apartment construction cost index $\left(P S_{t}\right)$. Since we indexed the price per square foot of structure with the ABCPI to get an approximate value of structure price for each period $t$, our structure price index $\left(I S_{t}\right)$ is implicitly estimated by the ABCPI based to Q1 $1996=100$ :

$$
I S_{t}=\frac{P S_{t}}{P S_{1}} \times 100=A B C P I_{t} ; \quad \mathrm{t}=1, \ldots, 55 .
$$

We start by calculating our total property price index using a fixed base Laspeyres price index formula, which is a basket index and widely used by statistical agencies, and it will also be used in compiling the NCAPI of Statistics Canada. To use our method for decomposing property value into land and structure components for the national balance sheets of a country, one would need weighting information on the stock of condominium apartments in the country. This information is difficult to obtain and so the weights we use in this study are the value shares of land and structures.

First, we calculate the predicated values of land $\left(L V_{t n}\right)$ and structures $\left(S V_{t n}\right)$ for $\mathrm{t}=1, \ldots, 55$ and $\mathrm{n}=1, \ldots, N_{t}$ :

$$
\begin{gathered}
L V_{t n}=\alpha t\left(\sum_{i=1}^{22} \theta_{i} F S A_{t n, i}\right)\left(1+\gamma\left(H_{t n}-1\right)\right)\left(1+\omega\left(T U_{t n}-9\right)\right)\left(\sum_{j=1}^{4} \vartheta_{j} T H_{t n, j}\right) \\
\left(\sum_{m=1}^{4} \sigma_{m} E L_{t n, m}\right)\left[\rho\left(\frac{S_{t n}}{T S_{t n}}\right)+(1-\rho)\left(\frac{1}{T U_{t n}}\right)\right] T L_{t n} \\
S V_{t n}=(1.33) P S_{t}(1-\delta)^{A_{t n}}\left(\sum_{k=1}^{3} \tau_{k} B D_{t n, k}\right)\left(\sum_{c=1}^{3} \varphi_{c} B T_{t n, c}\right) \\
\left(\sum_{y=1}^{2} \pi_{y} B C_{t n, y}\right)\left(\sum_{z=1}^{2} \eta_{z} N G_{t n, z}\right) S_{t n} .
\end{gathered}
$$

In order to get total land and structure values for sales in period t, we sum the predicted values from Models (35) and (36) to get:

$$
\begin{aligned}
& L V_{t}=\sum_{n=1}^{N_{t}} L V_{t n} ; \quad \mathrm{t}=1, \ldots, 55 . \\
& S V_{t}=\sum_{n=1}^{N_{t}} S V_{t n} ; \quad \mathrm{t}=1, \ldots, 55 .
\end{aligned}
$$

We define the total property value of condominium sales for period $\mathrm{t}, V_{t}$, as the sum of the predicted values $L V_{t}$ and $S V_{t}$ :

$$
V_{t}=L V_{t}+S V_{t} ; \quad \mathrm{t}=1, \ldots, 55 .
$$

The fixed base Laspeyres index formula for period $\mathrm{t}$ can be written as follows:

$$
I_{t}=I L_{t}\left(\frac{L V_{1}}{V_{1}}\right)+I S_{t}\left(\frac{S V_{1}}{V_{1}}\right) ; \quad \mathrm{t}=1, \ldots, 55 .
$$

The land, structure and fixed base Laspeyres (or total property) price indices for sales of condominium units are illustrated in Figure 1.

We can see that land prices have increased 4.42 fold between Q1 1996 and Q3 2009. From discussions with potential users of our land index, including the Consumer Price 


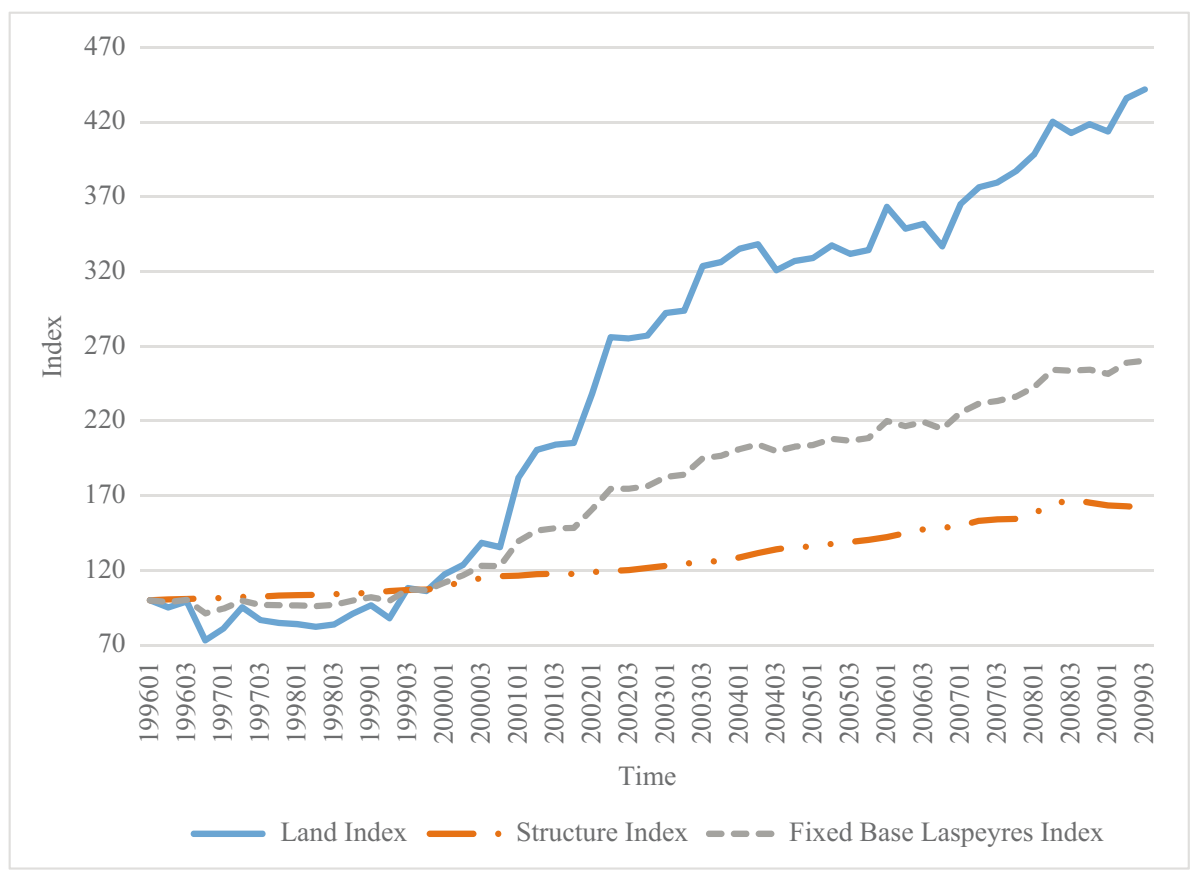

Fig. 1. Land, structure and fixed base Laspeyres price indices.

Index, the Canadian System of Macroeconomic Accounts, and other residential property price indices produced at Statistics Canada, these land results are deemed to be reasonable. This is the only condominium land price index of its kind in Canada, therefore, we cannot compare our results to any other land price index to legitimize them. However, other condominium price indices do exist that model the total property price of a unit. In Subsection 6.3, we will compare our total property price index to other indices that use different methods of calculation, but use the same variables as used in Model (31).

\subsection{Land and Structure Value Shares and Alternative Total Property Price Indices}

Before we go any further in comparing total property price indices, we have to decide which formula we will use to calculate our hedonically imputed index. The fixed base Laspeyres index shown in Figure 1 is misleading because over the 1996 to 2009 period, the land and structure value shares of condo sales change dramatically, as shown in Figure 2.

We can see that at our base period, Q1 1996, the structure component has a $65 \%$ share of the total value. However, as of Q1 2001, land takes over the majority share. This means that if we were to calculate a fixed base Paasche or a Fisher Index, the total property price index will look quite different. Figure 3 illustrates the difference between the fixed base Laspeyres, Paasche and Fisher indices calculated from our land and structure price and value estimates from Model (31).

Note that the fixed base Paasche and Fisher indices are higher than the Laspeyres. This is counter intuitive to most cases, where we see that the Paasche and Fisher indices are lower than the Laspeyres because of change in consumption patterns and weighting due to 


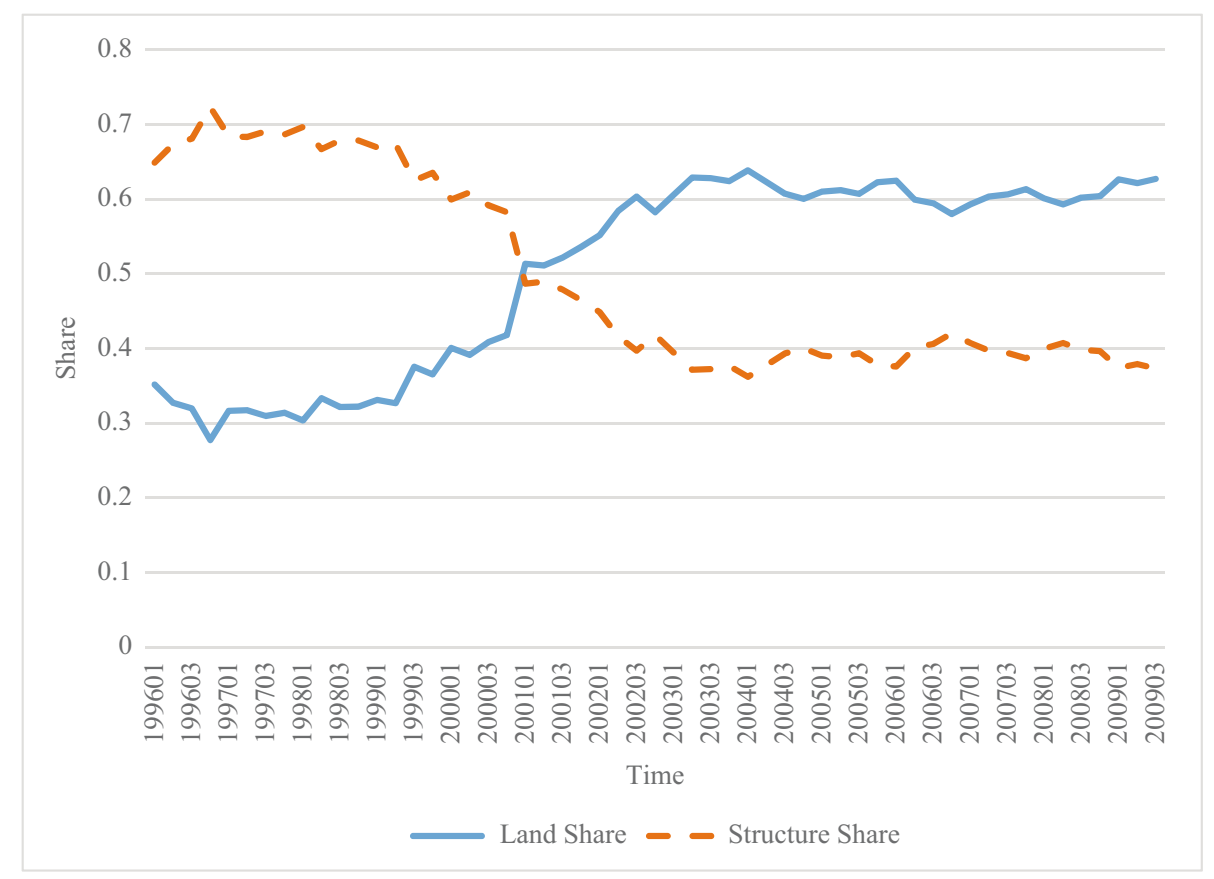

Fig. 2. Land and structure value shares over time.

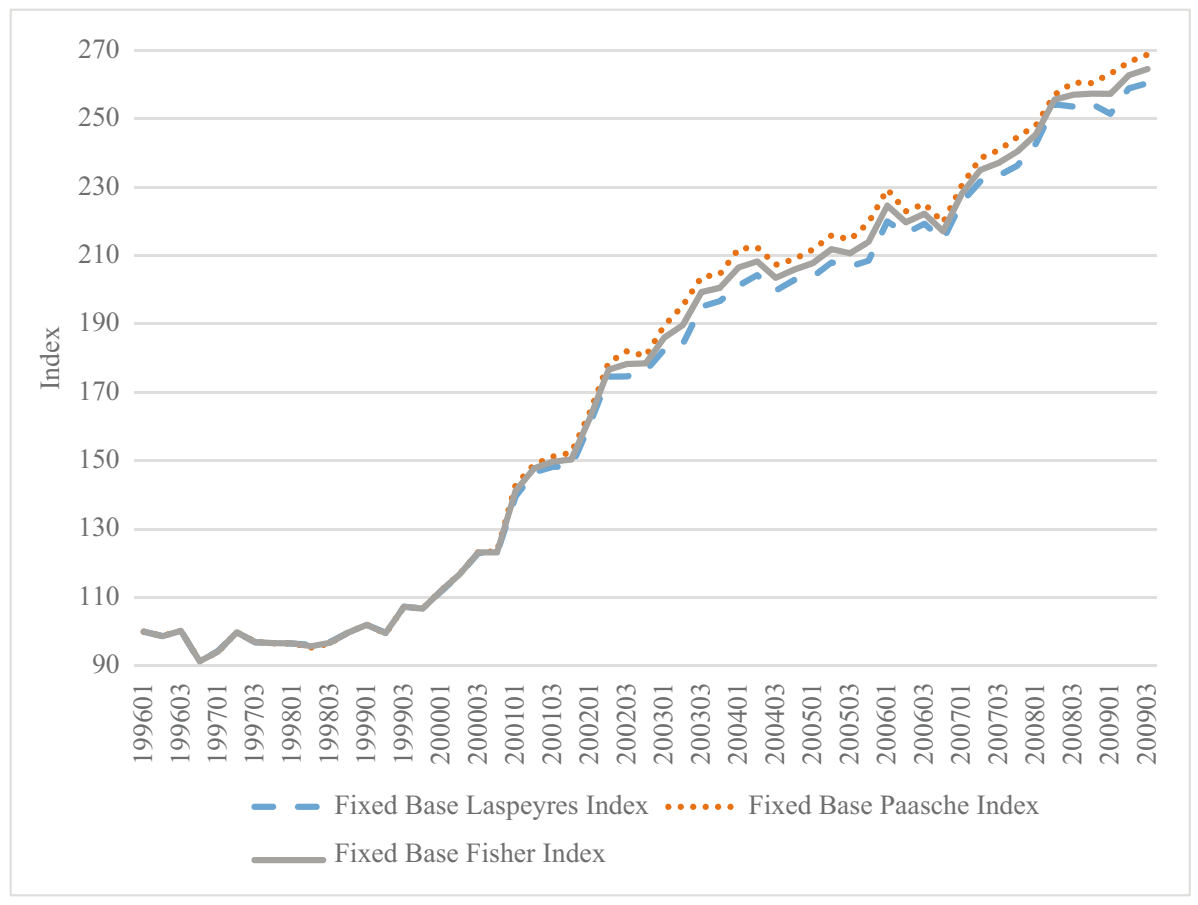

Fig. 3. Fixed base Laspeyres, Paasche and Fisher total property price indices. 
preferences towards cheaper goods. However, starting in 2001, the land value share is dominant, meaning that the land value, which exhibits much more growth than the structure value, gets a higher weight.

Due to this phenomenon in weighting patterns, a chained index would display different results than its fixed counterpart. Figure 4 illustrates the differences between the chained and fixed base Laspeyres.

With weights in the chained Laspeyres being more timely than its fixed base counterpart, they are more representative for each comparison period, reflecting the changes in the land share over time.

In Figure 5. Chained Laspeyres versus Paasche price index, we see, using the chained methodology, that the Laspeyres index is higher than the Paasche, which follows traditional index theory (Diewert 2009).

Also, as predicted, the spread between the Laspeyres and Paasche is dramatically reduced, which is clearly shown in Figure 5. The chained indices more closely approximate each other than the fixed base indices, such that we chose not to illustrate the chained Fisher index in Figure 5 because it would be indistinguishable between its Laspeyres and Paasche counterparts. However, we also need to point out, with some bounces in the land prices, the chained indices could suffer a certain degree of chain drift.

\subsection{Comparison With Other Total Property Indices}

As mentioned in Subsection 6.1, we do not have any other official land price indices that can be compared to our land price index. However, we can compare our fixed base and

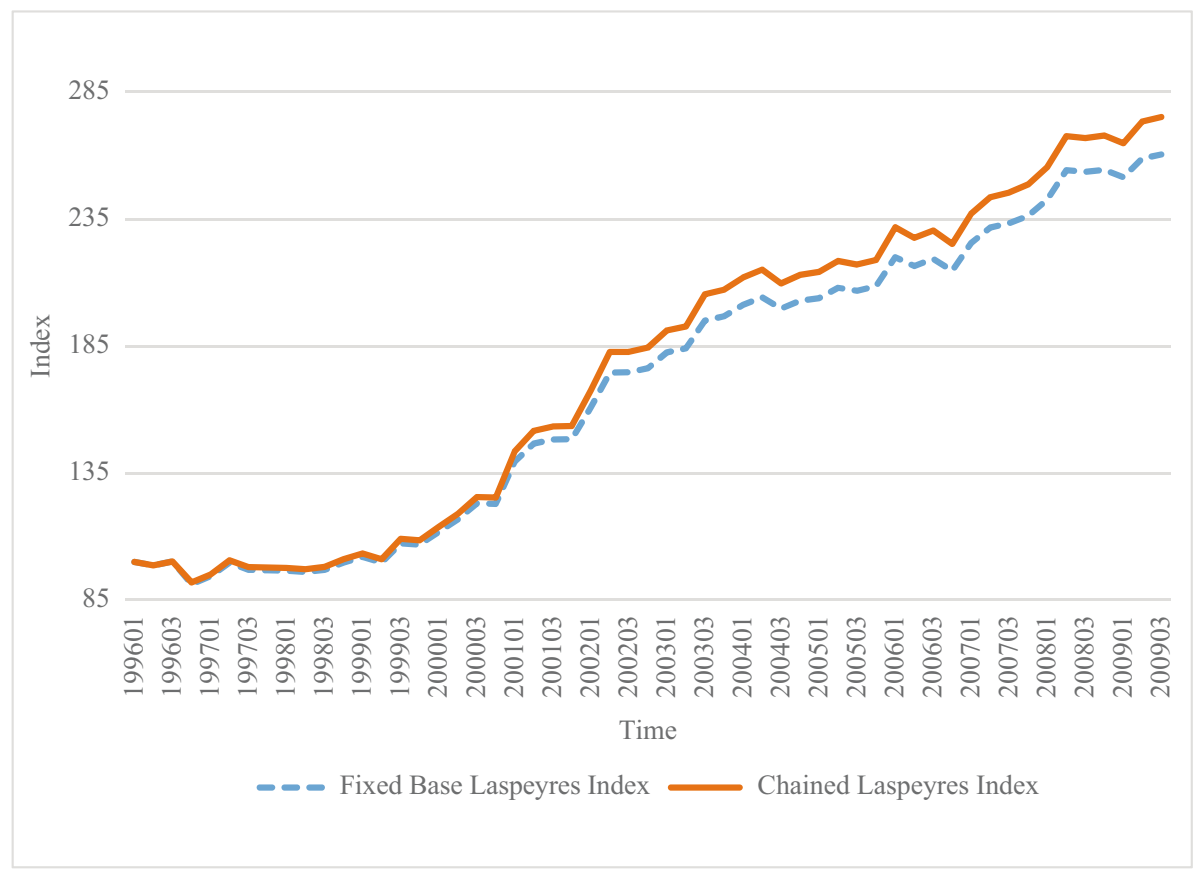

Fig. 4. Chained versus fixed base Laspeyres price indices. 


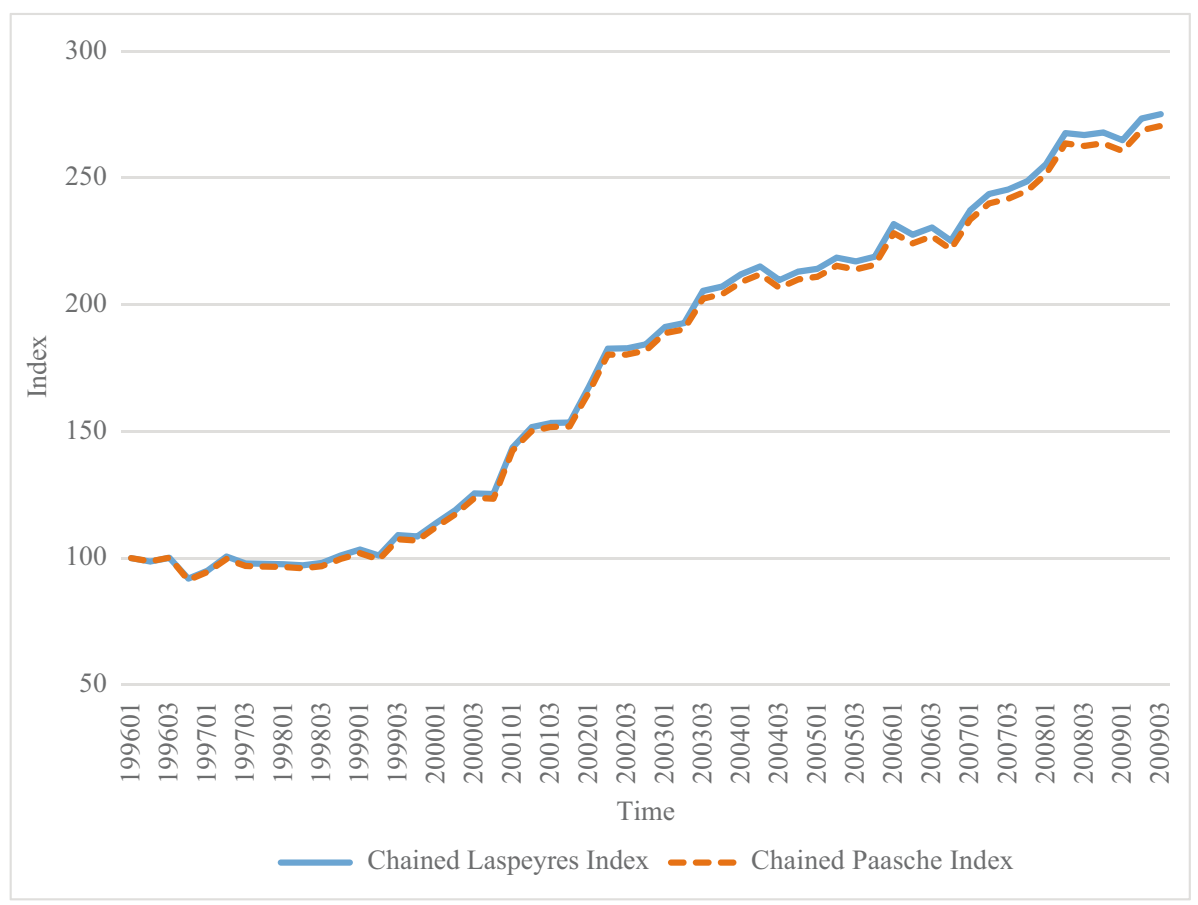

Fig. 5. Chained Laspeyres versus Paasche price index.

chained Fisher indices from Subsection 6.2 to total property indices calculated by other traditional methods, which are explained in detail in De Haan and Diewert (2013, 50-64), using the same explanatory variables.

First, we will compare our Fisher indices to three hedonic indices calculated by the following methods: the Pooled Time Dummy hedonic method, the Rolling Window Time Dummy hedonic method and the Hedonic Imputation approach. Hedonic methods have become a preferred method of constructing constant quality housing price indices, even though the data requirements are extensive and often expensive to obtain. All these hedonic methods regress the logarithm of selling price on selected characteristics for a certain time span, either a quarter, a year or all the periods under examination.

The characteristics that we included in these hedonic models are the same as were used in the Builder's Model (31). These characteristics reflect both quantitative and qualitative housing features that determine condominium prices. Figure 6 compares the different condo price indices for Ottawa using a traditional pooled time dummy hedonic regression.

The Pooled Time Dummy method runs a single regression on both characteristics variables and time dummy variables. It is very simple to apply in practice. The price index can be obtained directly from the estimated regression equation. The dependent variable is the logarithm of the unit's selling price and the overall price index is obtained by taking the exponential of the time dummy coefficients.

A practical problem associated with the hedonic regression model is the reassessment of the parameters with more recent data available. Figure 7 illustrates the Chained Fisher price index with a Rolling Window and a Hedonic Imputation Index. 


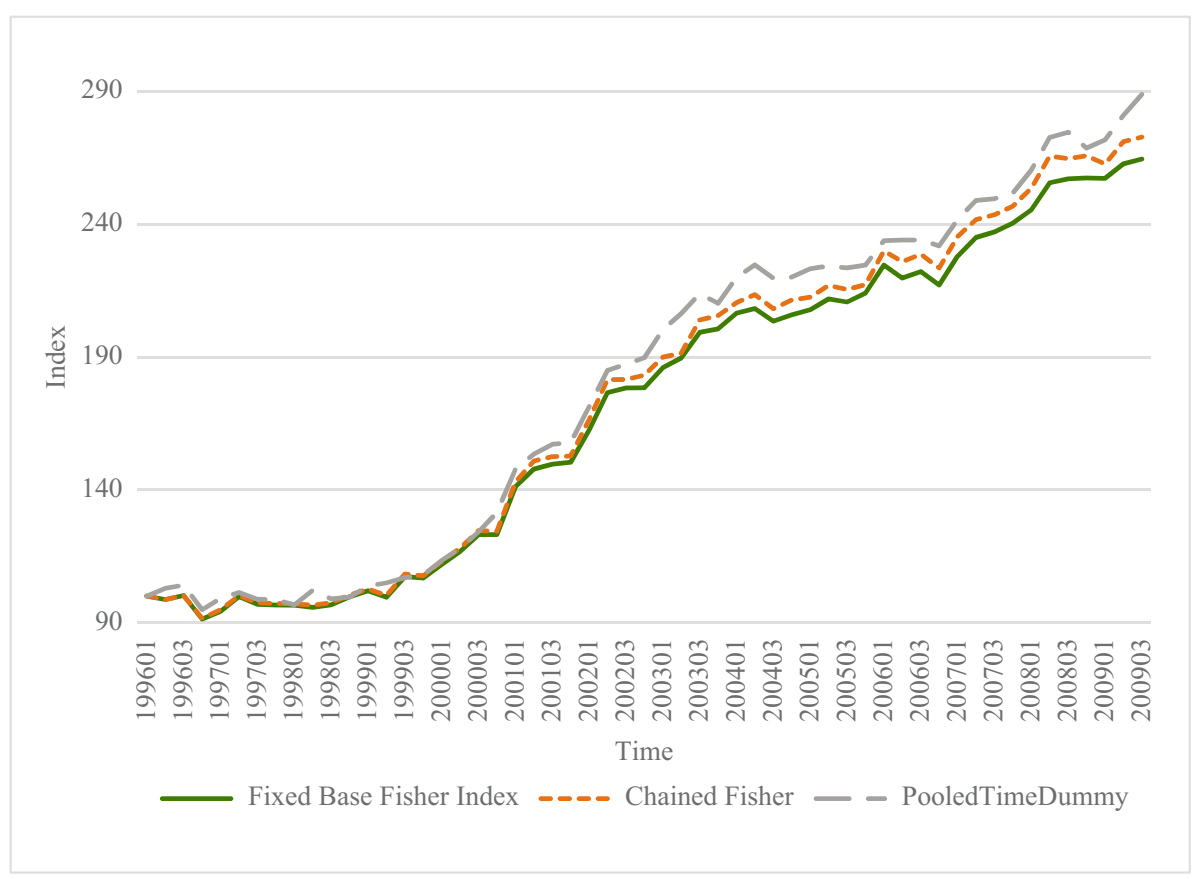

Fig. 6. Total property Fisher indices versus alternative hedonic regression base indices.

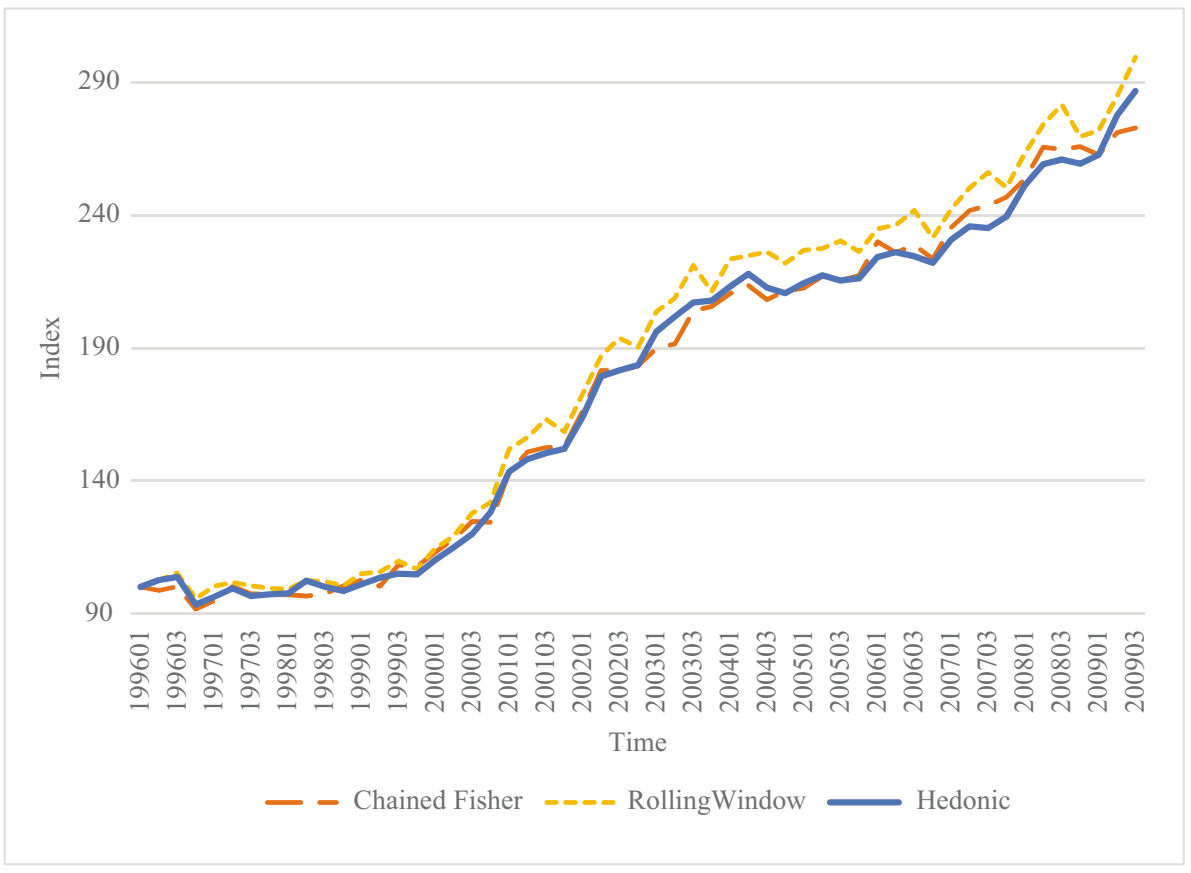

Fig. 7. Fixed base Fisher versus rolling window hedonic index and hedonic imputation Fisher index. 
The Rolling Window approach is a simple solution to this problem. The Rolling Window Time Dummy method is similar to the Pooled Time Dummy method, with the difference that the Rolling Window Method runs a sequence of hedonic regressions for a fixed-window length, such as a year. This length of the window is determined when the model yields relatively robust estimates. We applied Rolling Window procedure with a length of five quarters. The advantage of this method over the Pooled Time Dummy method is that the Rolling Window method allows for gradual changes in consumer tastes or preferences over time.

In order to implement the Hedonic Imputation approach, a separate hedonic regression is run using the data for each period. In general, a set of fixed quantity of characteristics of a standard or matched model are chosen to impute the missing prices using the estimated coefficients from the hedonic regression model. Based on which time period the fixed characteristics belong to, the Laspeyres, Paasche and Fisher imputation indices can be estimated. The chained Fisher index calculated by using the Hedonic Imputation method (labeled Hedonic Imputation Fisher) is shown in Figure 7. We found that all three alternative hedonic indices generally approximate each other fairly closely.

From Figure 6 and Figure 7 we can see that the Fisher indices, calculated from our nonlinear Model (31), follow the same long-term trend as the Pooled Time Dummy, Rolling Window and Hedonic Imputation models. The fixed base Fisher and the chained Fisher indices exhibit a 1.69 and 1.76 fold increase, respectively, between Q1 1996 and Q3 2009. This is less than the total growth of the three alternative hedonic models. Specifically, the fixed base Fisher index has a 169\% increase, the chained Fisher index has a $176 \%$ increase, the Pooled Time Dummy Index has a $188.9 \%$ increase, the Rolling Window Index has a $199.5 \%$ increase, and the Hedonic Imputation Method has a $186.7 \%$ increase. All four indices do have similar quarterly movements with an average growth rate of roughly $2 \%$ over the 14-year period.

The concern with using log-linear regression models such as the Pooled Time Dummy, Rolling Window and Hedonic Imputation models is that there can be multicollinearity between the variables, causing misleading coefficient estimates, which are then used to calculate the indices themselves. Therefore, we want to compare our Fisher Index to three indices using the following stratification methods: Mean Index and Median Index stratified by postal code and weighted by the sales in each quarter and the Median Index using stratification method proposed by Prasad and Richards (2006). These methods revolve around compiling a condominium price index using the mean or median price of each period. This methodology is simple and requires little information. However, this type of index has many disadvantages, such as it cannot fully account for quality change, and the compositional change of the housing stock will affect the price indices. Appropriate stratification can reduce bias caused by this compositional change.

Location is one of the natural stratification variables to use. We test the impact of using different fineness of classification schemes as the stratification indicator, with the finest neighbourhood variable in our data called district, the second finest called ward and the largest area in our data called FSA. Since condominium units are sold more frequently in certain areas and less frequently in the others, the alternative indices exhibit different price change patterns in different locations, which indicates that keeping the homogeneity of each cell is very important for the accuracy of the index. However, when the stratification scheme 


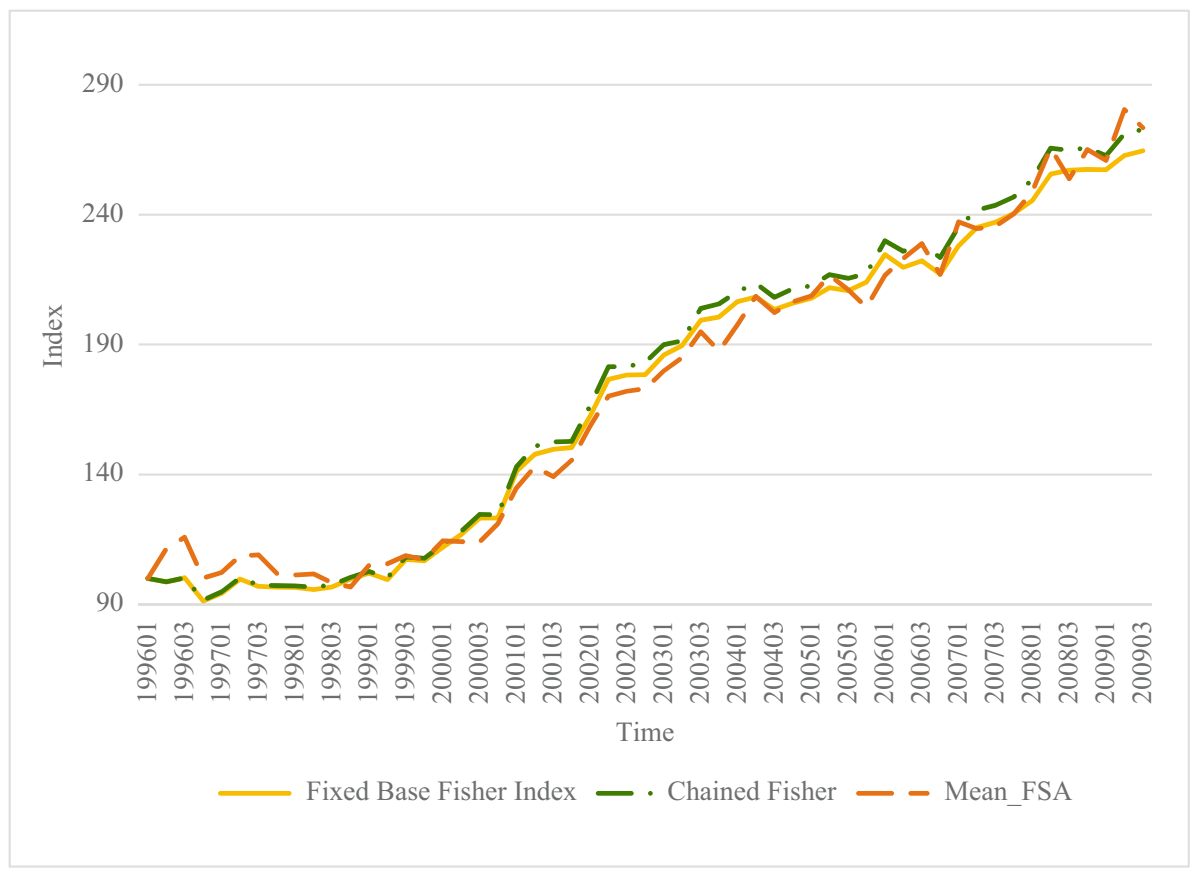

Fig. 8. Fisher indices versus mean index.

is too fine, empty cells will occur for some periods. If the classification scheme is very coarse, we cannot sufficiently control the homogeneity of the cell. The stratified price series reported in the article use FSA as the stratification variable. Figure 8, Figure 9, and Figure 10 illustrate the comparison between our Fisher indices and the Mean Index (Mean_FSA), Median Index (Med_FSA), and Median Index proposed by Prasad and Richards (Med (P\&R)).

The period-to-period movements vary between the five indices. However, the long-term trends are similar across all five indices. It can be seen that there are more fluctuations in the Median index stratified by FSA, especially after the first quarter of 2006, than those in the other four price series. This might be a result of using sales as the weight to aggregate indices across different FSA.

\section{Conclusion}

The most important conclusion from this study is that we now have a method to create land price indices for condominium units. Moreover, our estimated structure price index can be harmonized with current structure price indices that are used in the System of National Accounts. Condominium land and building characteristics data are difficult to find in Canada and attaining these data is a hurdle in putting the Builder's Model into practice. If the required information is obtained, we could apply this method to fill the missing gaps in the production of Statistics Canada's New Condominium Apartment Price Index and future residential property price indices. Though we cannot fully determine the accuracy of our land index by comparing to other sources, because no such sources exist, the similarities between the Fisher indices created from our Builder's Model and other hedonic and stratification methods, are promising for our proposed method of index calculation. 


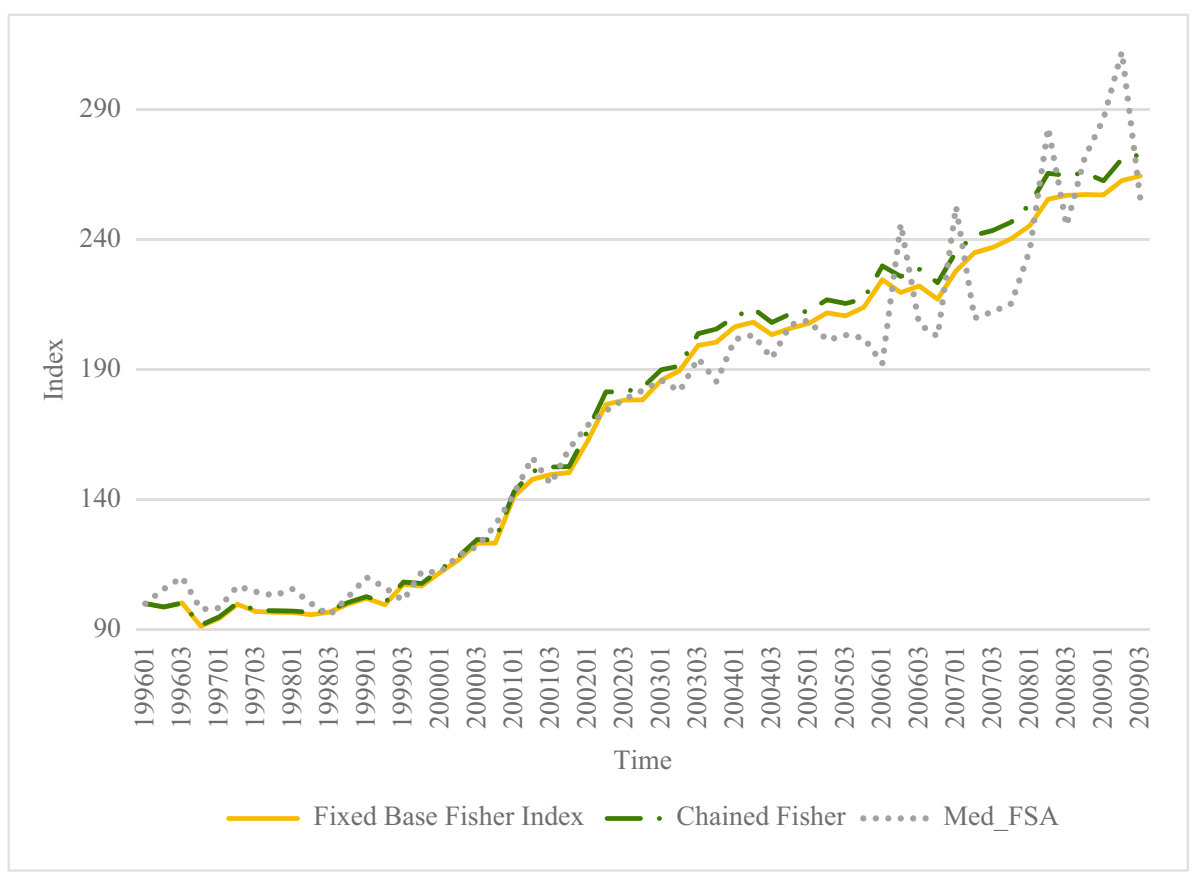

Fig. 9. Fixed base and chained Fisher indices versus median FSA index.

Through our modeling, we narrowed down the significant determinants of land prices to include location (determined by FSA), unit height, number of units in the building, building height and excess land. Our measurement of location by using FSA dummy

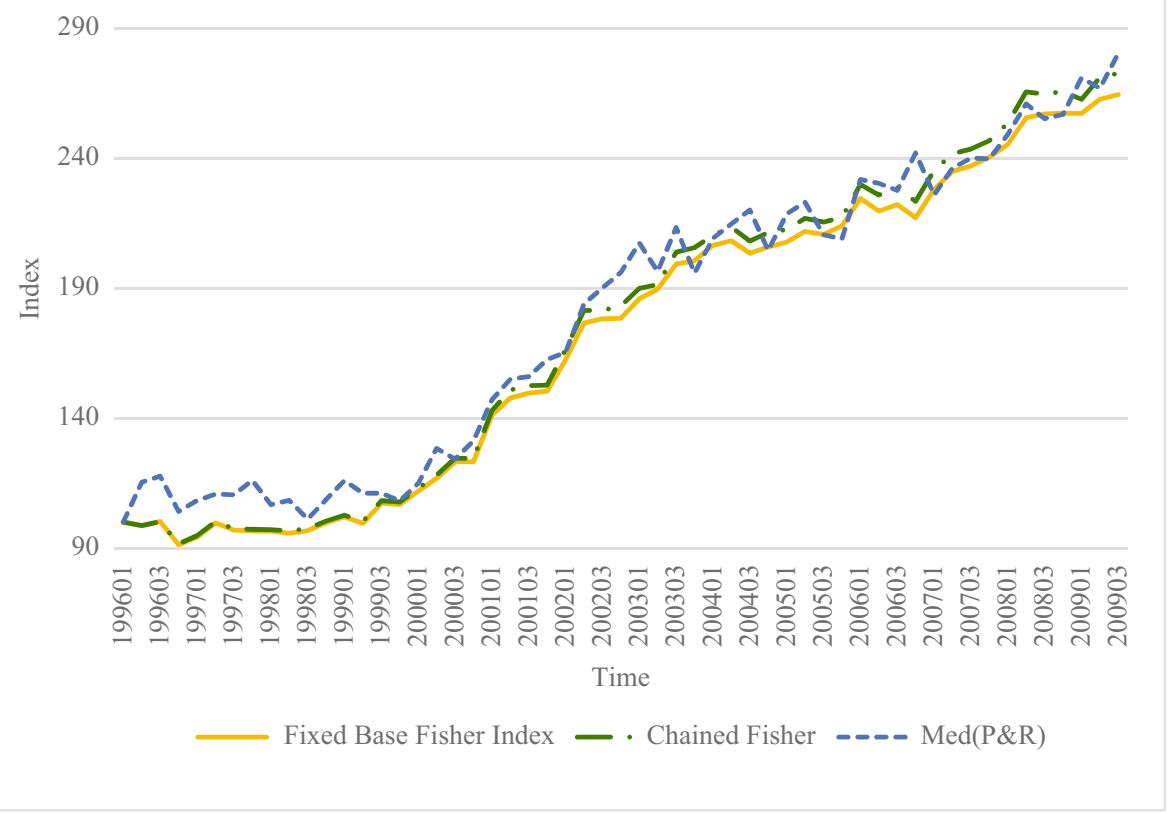

Fig. 10. Fixed base and chained Fisher indices versus median $(P \& R)$ index. 
variables is rather discrete. To improve our assessment of location, including neighborhood characteristics, this model will need to be applied to other geographic areas.

We also identified structure quality adjustment variables, such as the number of bedrooms, number of bathrooms, the presence of a balcony and natural gas heating in a condominium unit that impact price. Many other variables, such as dens, hardwood floors, condo fees and on-suite bathrooms were tested in our Builder's Model that appeared to have little impact. Comparing with the variables included in the model of Diewert and Shimizu (2016), we believe that the city characteristics will also have an impact on determining the choice of variables added to the Builder's Model. For instance, due to the long winters in Ottawa, the means of heating is an important feature for determining the price of condominium units. All these findings could be helpful for designing a survey to effectively collect required information at a minimum cost.

Lastly, we determined a net geometric depreciation rate of $2.4 \%$ for the Q1 1996 to Q3 2009 period. This value is slightly larger than that currently used by the Canadian System of National Accounts. As noted earlier, demolition depreciation is neglected in our model and so a geometric depreciation rate of $2.4 \%$ should be regarded as a lower bound on the overall depreciation rate. This exercise highlights that not only can the Builder's Model provide a land price index for the National Accounts, but it can also provide additional beneficial statistics for other parts of the System of National Accounts.

\section{Appendix}

8.1. Appendix 1: Regression Results Using 20, 25 and 30\% Communal Space in Model 22

Table 5. Regression results using 20, 25 and 30\% communal space in model 22.

\begin{tabular}{|c|c|c|c|c|c|c|}
\hline \multirow[b]{2}{*}{ Coefficient } & \multicolumn{2}{|c|}{$20 \%$} & \multicolumn{2}{|c|}{$25 \%$} & \multicolumn{2}{|c|}{$30 \%$} \\
\hline & Estimate & $\mathrm{T}$ stat & Estimate & $\mathrm{T}$ stat & Estimate & $\mathrm{T}$ stat \\
\hline$\hat{\theta}_{1}$ & 92.3106 & 6.14 & 87.9885 & 6.07 & 82.9916 & 5.98 \\
\hline$\hat{\theta}_{2}$ & 109.845 & 8.69 & 105.601 & 8.54 & 100.551 & 8.35 \\
\hline$\hat{\theta}_{3}$ & 115.028 & 8.48 & 110.461 & 8.34 & 105.055 & 8.16 \\
\hline$\hat{\theta}_{4}$ & 70.1347 & 8.45 & 67.0257 & 8.31 & 63.4037 & 8.13 \\
\hline$\hat{\theta}_{5}$ & 99.8556 & 8.67 & 96.0765 & 8.51 & 91.619 & 8.33 \\
\hline$\hat{\theta}_{6}$ & 86.4793 & 8.59 & 83.3044 & 8.44 & 79.5637 & 8.26 \\
\hline$\hat{\theta}_{7}$ & 126.78 & 8.62 & 122.255 & 8.47 & 116.863 & 8.29 \\
\hline$\hat{\theta}_{8}$ & 193.445 & 8.76 & 186.962 & 8.6 & 179.208 & 8.41 \\
\hline$\hat{\theta}_{9}$ & 163.113 & 8.73 & 157.525 & 8.57 & 150.892 & 8.39 \\
\hline$\hat{\theta}_{10}$ & 224.005 & 8.66 & 216.273 & 8.51 & 207.065 & 8.33 \\
\hline$\hat{\theta}_{11}$ & 92.7051 & 8.24 & 88.5551 & 8.1 & 83.6586 & 7.93 \\
\hline$\hat{\theta}_{12}$ & 110.906 & 8.67 & 106.395 & 8.52 & 101.075 & 8.33 \\
\hline$\hat{\theta}_{13}$ & 150.972 & 8.72 & 145.54 & 8.57 & 139.11 & 8.38 \\
\hline$\hat{\theta}_{14}$ & 280.319 & 8.69 & 271.132 & 8.54 & 260.187 & 8.35 \\
\hline$\hat{\theta}_{15}$ & 160.981 & 8.63 & 155.352 & 8.48 & 148.691 & 8.3 \\
\hline$\hat{\theta}_{16}$ & 101.275 & 8.67 & 97.4698 & 8.52 & 92.9864 & 8.33 \\
\hline$\hat{\theta}_{17}$ & 100.839 & 8.5 & 96.7042 & 8.35 & 91.8581 & 8.17 \\
\hline$\hat{\theta}_{18}$ & 119.712 & 8.69 & 115.267 & 8.53 & 110.042 & 8.35 \\
\hline$\hat{\theta}_{19}$ & 110.827 & 8.65 & 106.175 & 8.5 & 100.758 & 8.31 \\
\hline
\end{tabular}


Table 5. Continued

\begin{tabular}{|c|c|c|c|c|c|c|}
\hline \multirow[b]{2}{*}{ Coefficient } & \multicolumn{2}{|c|}{$20 \%$} & \multicolumn{2}{|c|}{$25 \%$} & \multicolumn{2}{|c|}{$30 \%$} \\
\hline & Estimate & T stat & Estimate & $\mathrm{T}$ stat & Estimate & $\mathrm{T}$ stat \\
\hline$\hat{\theta}_{20}$ & 133.896 & 7.66 & 128.443 & 7.55 & 122.009 & 7.41 \\
\hline$\hat{\theta}_{21}$ & 206.157 & 8.76 & 199.379 & 8.61 & 191.291 & 8.42 \\
\hline$\hat{\theta}_{22}$ & 148.594 & 7.28 & 142.856 & 7.19 & 136.031 & 7.07 \\
\hline$\hat{\alpha}_{2}$ & 1.04534 & 7.14 & 1.04778 & 7.01 & 1.05093 & 6.85 \\
\hline$\hat{\alpha_{3}}$ & 1.13726 & 7.1 & 1.14015 & 6.98 & 1.14385 & 6.83 \\
\hline$\hat{\alpha}_{4}$ & 0.87045 & 5.41 & 0.86845 & 5.3 & 0.86598 & 5.17 \\
\hline$\hat{\alpha}_{5}$ & 0.83845 & 8 & 0.83843 & 7.83 & 0.83853 & 7.63 \\
\hline$\hat{\alpha}_{6}$ & 1.03381 & 7.34 & 1.03479 & 7.2 & 1.03622 & 7.03 \\
\hline$\hat{\alpha}_{7}$ & 0.96328 & 7.1 & 0.96336 & 6.96 & 0.96362 & 6.78 \\
\hline$\hat{\alpha}_{8}$ & 0.92834 & 6.32 & 0.928 & 6.19 & 0.92777 & 6.02 \\
\hline$\hat{\alpha}_{9}$ & 0.93718 & 6.77 & 0.93608 & 6.63 & 0.93483 & 6.46 \\
\hline$\hat{\alpha}_{10}$ & 0.79378 & 8.5 & 0.79269 & 8.34 & 0.79131 & 8.15 \\
\hline$\hat{\alpha}_{11}$ & 0.8809 & 6.68 & 0.87994 & 6.53 & 0.87897 & 6.35 \\
\hline$\hat{\alpha}_{12}$ & 0.96838 & 5.28 & 0.96732 & 5.18 & 0.96622 & 5.07 \\
\hline$\hat{\alpha}_{13}$ & 1.00982 & 7.23 & 1.01083 & 7.09 & 1.0124 & 6.92 \\
\hline$\hat{\alpha}_{14}$ & 0.88547 & 8.55 & 0.88524 & 8.4 & 0.88503 & 8.2 \\
\hline$\hat{\alpha}_{15}$ & 1.02688 & 7.69 & 1.02897 & 7.54 & 1.032 & 7.36 \\
\hline$\hat{\alpha}_{16}$ & 1.03449 & 6.73 & 1.03658 & 6.62 & 1.03962 & 6.48 \\
\hline$\hat{\alpha}_{17}$ & 1.08156 & 7.49 & 1.08566 & 7.36 & 1.09134 & 7.2 \\
\hline$\hat{\alpha}_{18}$ & 1.13656 & 8.09 & 1.14082 & 7.94 & 1.14671 & 7.76 \\
\hline$\hat{\alpha}_{19}$ & 1.20013 & 7.43 & 1.20469 & 7.29 & 1.21098 & 7.13 \\
\hline$\hat{\alpha}_{20}$ & 1.13941 & 8.59 & 1.14462 & 8.44 & 1.15142 & 8.25 \\
\hline$\hat{\alpha}_{21}$ & 1.36364 & 8.66 & 1.37589 & 8.51 & 1.39192 & 8.32 \\
\hline$\hat{\alpha}_{22}$ & 1.54022 & 8.45 & 1.55556 & 8.3 & 1.57576 & 8.12 \\
\hline$\hat{\alpha}_{23}$ & 1.53205 & 8.29 & 1.54807 & 8.15 & 1.56913 & 7.97 \\
\hline$\hat{\alpha}_{24}$ & 1.51548 & 8.52 & 1.53228 & 8.37 & 1.55434 & 8.19 \\
\hline$\hat{\alpha}_{25}$ & 1.76457 & 8.61 & 1.7875 & 8.46 & 1.81741 & 8.27 \\
\hline$\hat{\alpha}_{26}$ & 1.9749 & 8.61 & 2.00419 & 8.46 & 2.04237 & 8.28 \\
\hline$\hat{\alpha}_{27}$ & 1.9082 & 8.57 & 1.93553 & 8.42 & 1.97113 & 8.24 \\
\hline$\hat{\alpha}_{28}$ & 1.96541 & 8.49 & 1.99381 & 8.35 & 2.0308 & 8.17 \\
\hline$\hat{\alpha}_{29}$ & 2.04157 & 8.58 & 2.07241 & 8.44 & 2.11263 & 8.26 \\
\hline$\hat{\alpha}_{30}$ & 1.94756 & 8.75 & 1.97596 & 8.6 & 2.01269 & 8.41 \\
\hline$\hat{\alpha}_{31}$ & 2.1943 & 8.66 & 2.22967 & 8.51 & 2.27582 & 8.33 \\
\hline$\hat{\alpha}_{32}$ & 2.19107 & 8.58 & 2.22528 & 8.43 & 2.26984 & 8.25 \\
\hline$\hat{\alpha}_{33}$ & 2.24306 & 8.7 & 2.27907 & 8.55 & 2.32605 & 8.36 \\
\hline$\hat{\alpha}_{34}$ & 2.29486 & 8.73 & 2.33091 & 8.58 & 2.37799 & 8.39 \\
\hline$\hat{\alpha}_{35}$ & 2.21382 & 8.69 & 2.24682 & 8.54 & 2.28992 & 8.35 \\
\hline$\hat{\alpha}_{36}$ & 2.25073 & 8.64 & 2.28557 & 8.49 & 2.33107 & 8.3 \\
\hline$\hat{\alpha}_{37}$ & 2.26801 & 8.72 & 2.30224 & 8.56 & 2.34699 & 8.38 \\
\hline$\hat{\alpha}_{38}$ & 2.29853 & 8.76 & 2.3341 & 8.6 & 2.38054 & 8.41 \\
\hline$\hat{\alpha}_{39}$ & 2.31549 & 8.71 & 2.35055 & 8.55 & 2.39645 & 8.37 \\
\hline$\hat{\alpha}_{40}$ & 2.32024 & 8.57 & 2.35537 & 8.42 & 2.40132 & 8.24 \\
\hline$\hat{\alpha}_{41}$ & 2.47301 & 8.74 & 2.5125 & 8.58 & 2.56415 & 8.39 \\
\hline$\hat{\alpha}_{42}$ & 2.46739 & 8.76 & 2.50482 & 8.6 & 2.55387 & 8.41 \\
\hline$\hat{\alpha}_{43}$ & 2.43186 & 8.75 & 2.46879 & 8.6 & 2.51717 & 8.41 \\
\hline$\hat{\alpha}_{44}$ & 2.39763 & 8.71 & 2.43322 & 8.55 & 2.47982 & 8.37 \\
\hline
\end{tabular}


Table 5. Continued

\begin{tabular}{|c|c|c|c|c|c|c|}
\hline \multirow[b]{2}{*}{ Coefficient } & \multicolumn{2}{|c|}{$20 \%$} & \multicolumn{2}{|c|}{$25 \%$} & \multicolumn{2}{|c|}{$30 \%$} \\
\hline & Estimate & T stat & Estimate & $\mathrm{T}$ stat & Estimate & $\mathrm{T}$ stat \\
\hline$\hat{\alpha}_{45}$ & 2.5445 & 8.76 & 2.5827 & 8.61 & 2.63271 & 8.42 \\
\hline$\hat{\alpha}_{46}$ & 2.63324 & 8.78 & 2.67442 & 8.62 & 2.72824 & 8.43 \\
\hline$\hat{\alpha}_{47}$ & 2.65067 & 8.76 & 2.69218 & 8.61 & 2.74652 & 8.42 \\
\hline$\hat{\alpha}_{48}$ & 2.67028 & 8.74 & 2.71348 & 8.59 & 2.77002 & 8.4 \\
\hline$\hat{\alpha}_{49}$ & 2.79316 & 8.76 & 2.83799 & 8.6 & 2.89673 & 8.42 \\
\hline$\alpha_{50}$ & 2.96019 & 8.79 & 3.00787 & 8.63 & 3.07045 & 8.44 \\
\hline$\hat{\alpha}_{51}$ & 2.83087 & 8.77 & 2.87605 & 8.61 & 2.93536 & 8.42 \\
\hline$\hat{\alpha}_{52}$ & 2.95191 & 8.77 & 2.99937 & 8.61 & 3.06159 & 8.42 \\
\hline$\hat{\alpha}_{53}$ & 2.83705 & 8.78 & 2.88212 & 8.62 & 2.94106 & 8.43 \\
\hline$\hat{\alpha}_{54}$ & 3.01506 & 8.79 & 3.06634 & 8.63 & 3.13345 & 8.44 \\
\hline$\hat{\alpha}_{55}$ & 2.93895 & 8.79 & 2.9895 & 8.63 & 3.05567 & 8.44 \\
\hline$\hat{\gamma}$ & 0.00834 & 13.51 & 0.00847 & 13.64 & 0.00864 & 13.8 \\
\hline$\hat{\omega}$ & 0.01004 & 39.23 & 0.01001 & 39 & 0.00995 & 38.71 \\
\hline$\hat{\vartheta}_{2}$ & 1.15636 & 106.96 & 1.15861 & 106.51 & 1.16203 & 105.98 \\
\hline$\hat{\vartheta}_{3}$ & 1.4345 & 77.2 & 1.4374 & 76.88 & 1.4423 & 76.52 \\
\hline$\hat{\vartheta}_{4}$ & 1.68029 & 69.79 & 1.68332 & 69.47 & 1.68884 & 69.1 \\
\hline$\hat{\sigma}_{2}$ & 0.54132 & 124.2 & 0.54203 & 123.74 & 0.54304 & 123.21 \\
\hline$\hat{\sigma_{3}}$ & 0.27106 & 81.76 & 0.2718 & 81.31 & 0.27283 & 80.78 \\
\hline$\hat{\sigma}_{4}$ & 0.18369 & 55.92 & 0.18394 & 55.61 & 0.18437 & 55.26 \\
\hline$\hat{\rho}$ & 0.50292 & 57.1 & 0.49601 & 55.63 & 0.48743 & 53.84 \\
\hline$\hat{\delta}$ & 0.01035 & 9.5 & 0.01064 & 10.41 & 0.01105 & 11.63 \\
\hline
\end{tabular}

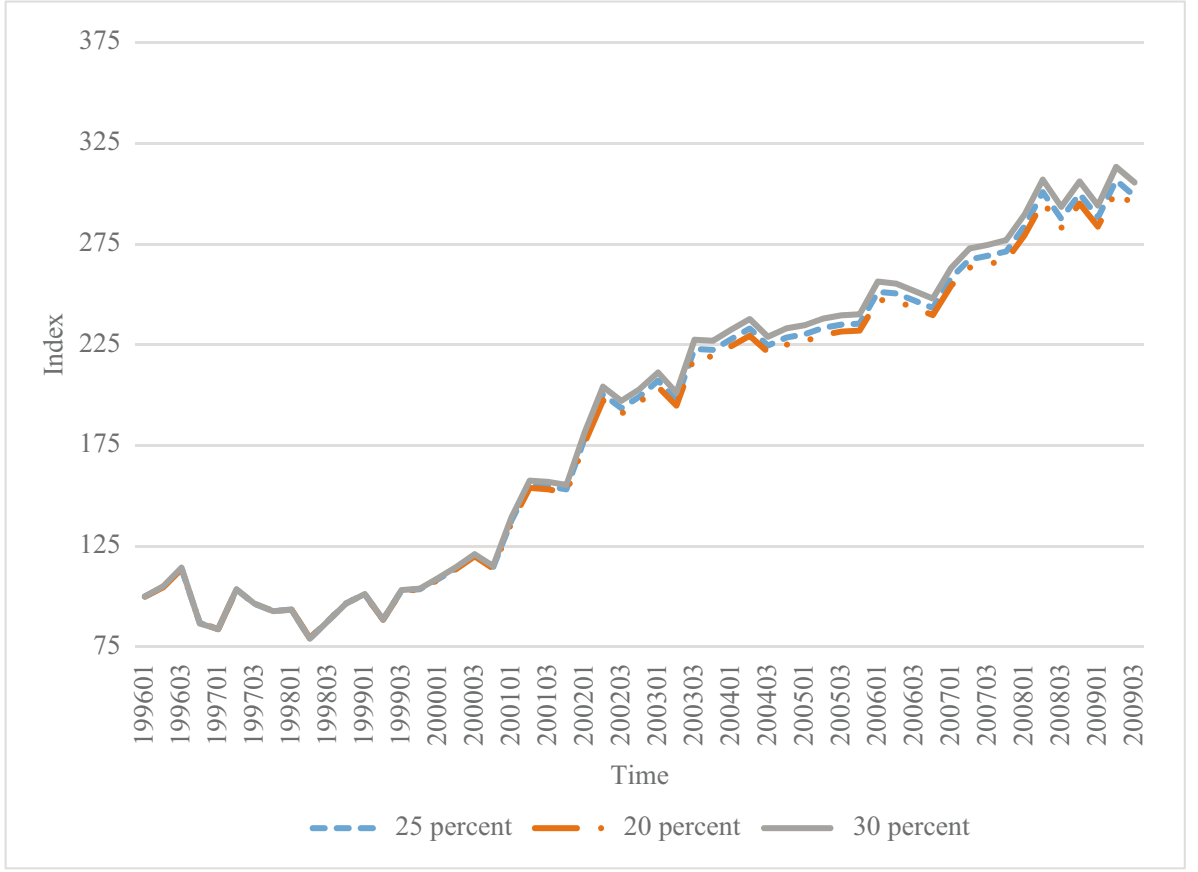

Fig. 11. Index results using 20, 25 and 30\% communal space in Model 21. 


\subsection{Appendix 2: Estimates of Model 5}

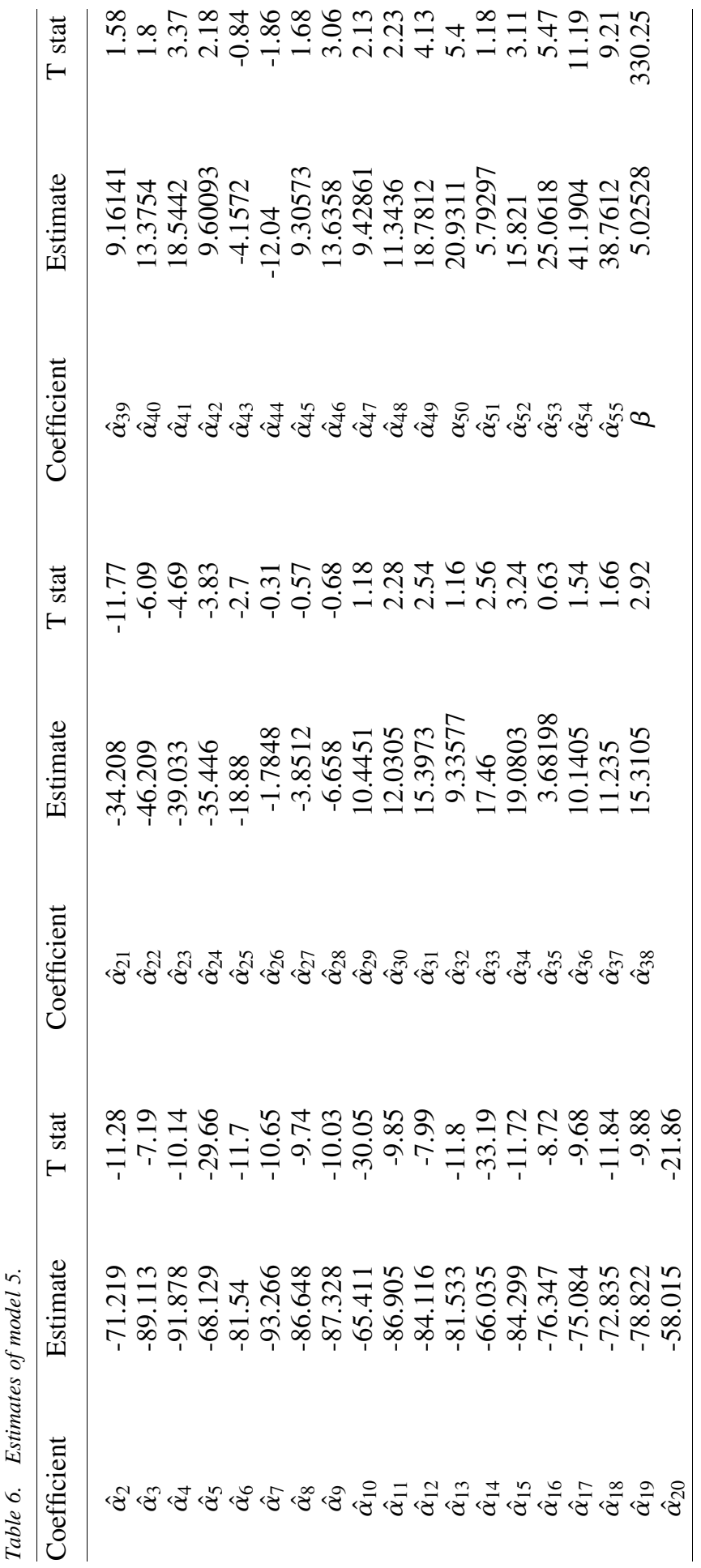




\subsection{Appendix 3: Estimates of Model 21}

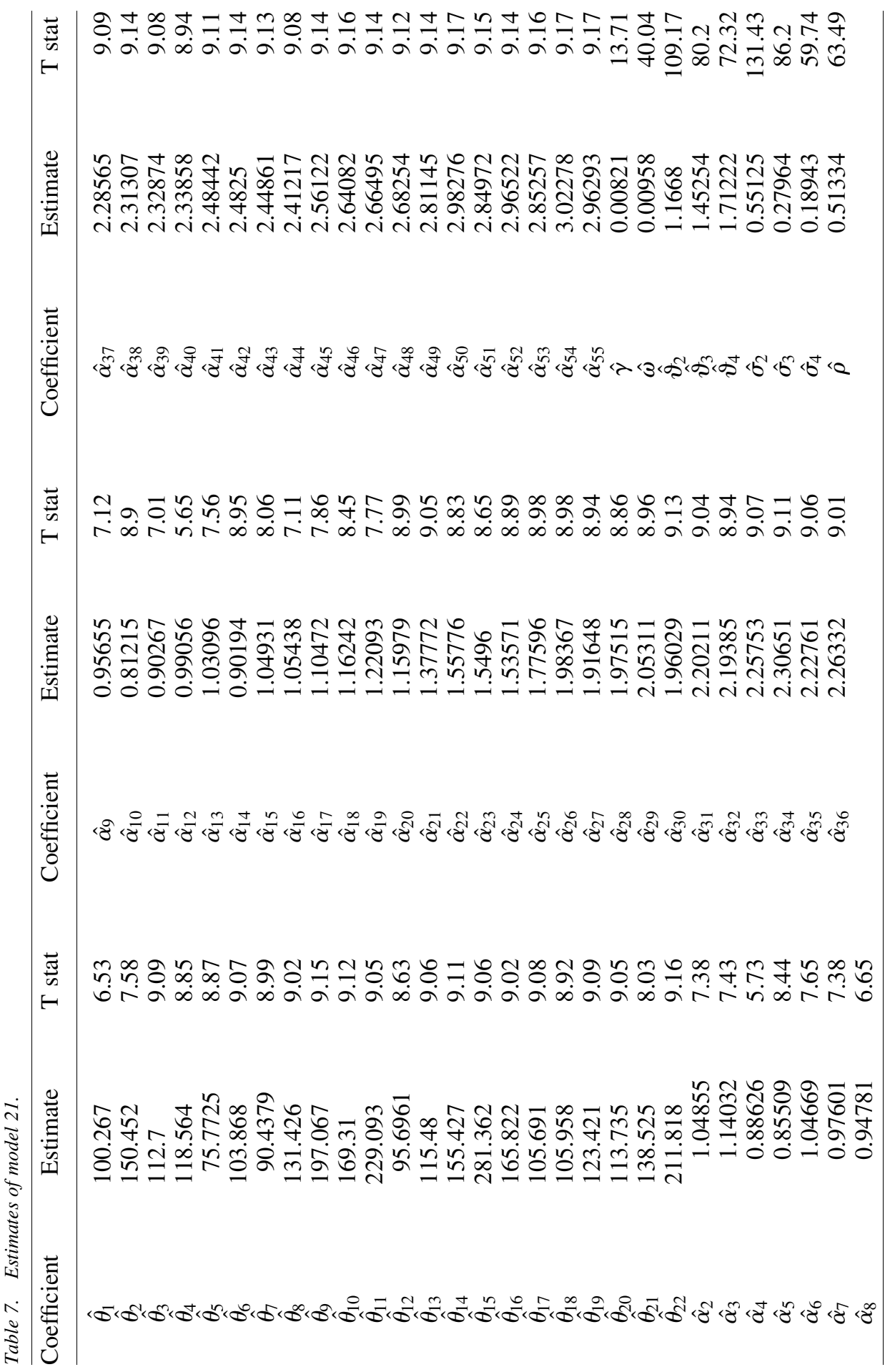




\subsection{Appendix 4: Estimates of Model 31}

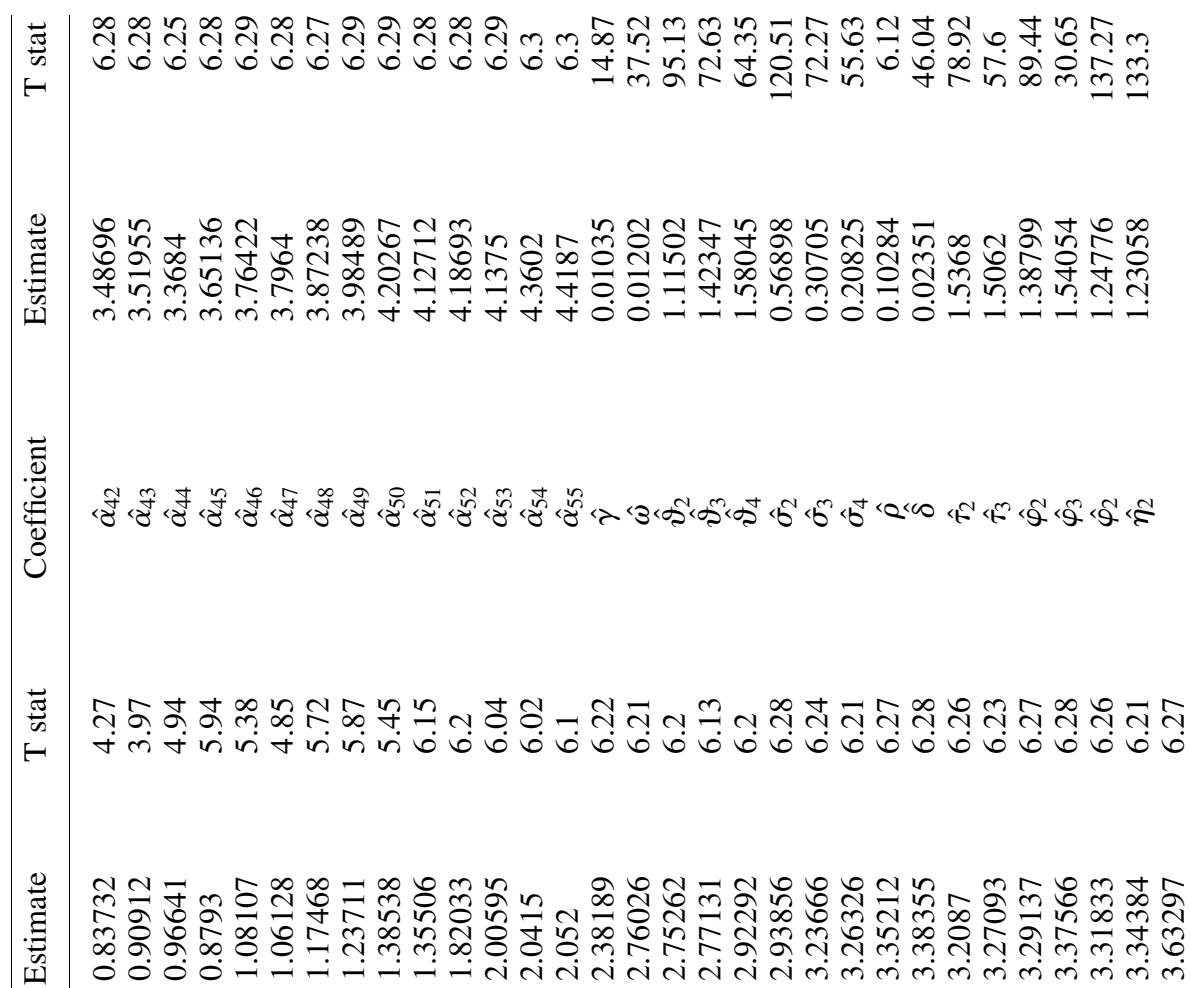

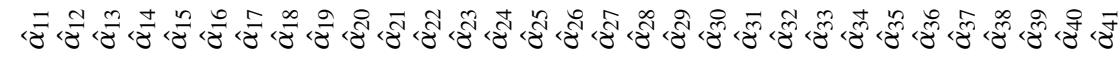

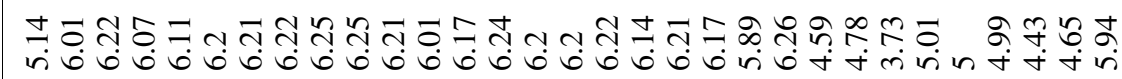

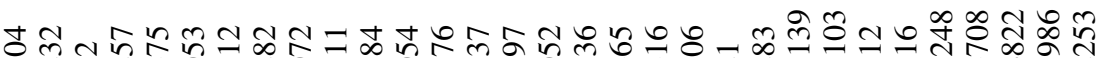

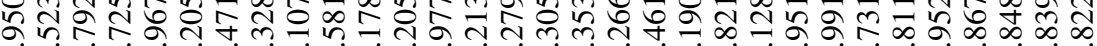

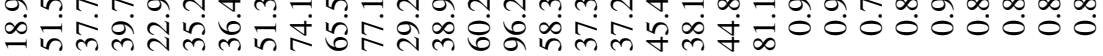

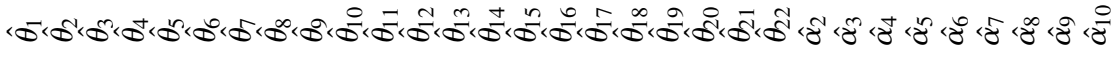


8.5. Appendix 5: Robustness Testing

Table 9. Determinants of land value over selected time periods.

\begin{tabular}{|c|c|c|c|c|c|c|}
\hline \multirow[b]{2}{*}{ Coefficient } & \multicolumn{2}{|c|}{$1996-2009$} & \multicolumn{2}{|c|}{$1996-2003$} & \multicolumn{2}{|c|}{$1996-2008$} \\
\hline & Estimate & $\mathrm{T}$ stat & Estimate & $\mathrm{T}$ stat & Estimate & $\mathrm{T}$ stat \\
\hline$\hat{\theta}_{1}$ & 100.267 & 6.53 & 79.9762 & 7.03 & 96.2423 & 7.24 \\
\hline$\hat{\theta}_{2}$ & 150.452 & 7.58 & 134.34 & 6.96 & 149.643 & 8.65 \\
\hline$\hat{\theta}_{3}$ & 112.7 & 9.09 & 97.7052 & 17.72 & 113.125 & 10.55 \\
\hline$\hat{\theta}_{4}$ & 118.564 & 8.85 & 110.558 & 16.23 & 120.625 & 10.28 \\
\hline$\hat{\theta}_{5}$ & 75.7725 & 8.87 & 56.7741 & 13.95 & 74.7073 & 10.09 \\
\hline$\hat{\theta}_{6}$ & 103.868 & 9.07 & 87.8267 & 18.37 & 102.814 & 10.56 \\
\hline$\hat{\theta}_{7}$ & 90.4379 & 8.99 & 77.1447 & 16.72 & 91.0148 & 10.46 \\
\hline$\hat{\theta}_{8}$ & 131.426 & 9.02 & 121.379 & 16.26 & 129.148 & 10.43 \\
\hline$\hat{\theta}_{9}$ & 197.067 & 9.15 & 168.239 & 19.1 & 200.93 & 10.67 \\
\hline$\hat{\theta}_{10}$ & 169.31 & 9.12 & 138.186 & 18.49 & 161.353 & 10.62 \\
\hline$\hat{\theta}_{11}$ & 229.093 & 9.05 & 223.235 & 15.58 & 228.791 & 10.5 \\
\hline$\hat{\theta}_{12}$ & 95.6961 & 8.63 & 89.0804 & 14.83 & 94.7354 & 9.97 \\
\hline$\hat{\theta}_{13}$ & 115.48 & 9.06 & 105.145 & 17.42 & 116.302 & 10.52 \\
\hline$\hat{\theta}_{14}$ & 155.427 & 9.11 & 120.623 & 18.15 & 154.305 & 10.62 \\
\hline$\hat{\theta}_{15}$ & 281.362 & 9.06 & - & - & 195.441 & 8.21 \\
\hline$\hat{\theta}_{16}$ & 165.822 & 9.02 & 143.66 & 16.69 & 165.004 & 10.44 \\
\hline$\hat{\theta}_{17}$ & 105.691 & 9.08 & 98.2246 & 17.98 & 107.777 & 10.55 \\
\hline$\hat{\theta}_{18}$ & 105.958 & 8.92 & 83.7896 & 16.98 & 103.171 & 10.33 \\
\hline$\hat{\theta}_{19}$ & 123.421 & 9.09 & 123.221 & 18.06 & 128.488 & 10.55 \\
\hline$\hat{\theta}_{20}$ & 113.735 & 9.05 & 106.728 & 16.39 & 158.293 & 10.43 \\
\hline$\hat{\theta}_{21}$ & 138.525 & 8.03 & 130.076 & 13.41 & 142.312 & 9.11 \\
\hline$\hat{\theta}_{22}$ & 211.818 & 9.16 & 175.516 & 19.39 & 211.934 & 10.69 \\
\hline$\hat{\alpha}_{2}$ & 1.04855 & 7.38 & 1.0622 & 15.95 & 1.04758 & 8.6 \\
\hline$\hat{\alpha_{3}}$ & 1.14032 & 7.43 & 1.1634 & 16.14 & 1.13939 & 8.53 \\
\hline$\hat{\alpha}_{4}$ & 0.88626 & 5.73 & 0.91482 & 12.67 & 0.88859 & 6.56 \\
\hline$\hat{\alpha}_{5}$ & 0.85509 & 8.44 & 0.93369 & 16.33 & 0.86639 & 9.72 \\
\hline$\hat{\alpha}_{6}$ & 1.04669 & 7.65 & 1.0606 & 16.84 & 1.04204 & 8.84 \\
\hline$\hat{\alpha}_{7}$ & 0.97601 & 7.38 & 1.01853 & 15.6 & 0.98682 & 8.54 \\
\hline$\hat{\alpha}_{8}$ & 0.94781 & 6.65 & 0.98542 & 13.82 & 0.94771 & 7.6 \\
\hline$\hat{\alpha}_{9}$ & 0.95655 & 7.12 & 0.97719 & 15.4 & 0.95759 & 8.33 \\
\hline$\hat{\alpha}_{10}$ & 0.81215 & 8.9 & 0.9148 & 19.02 & 0.82722 & 10.36 \\
\hline$\hat{\alpha}_{11}$ & 0.90267 & 7.01 & 0.94522 & 14.93 & 0.91103 & 8.08 \\
\hline$\hat{\alpha}_{12}$ & 0.99056 & 5.65 & 1.01007 & 12.76 & 0.98673 & 6.45 \\
\hline$\hat{\alpha}_{13}$ & 1.03096 & 7.56 & 1.06153 & 15.63 & 1.0276 & 8.65 \\
\hline$\hat{\alpha}_{14}$ & 0.90194 & 8.95 & 1.00404 & 19.1 & 0.9238 & 10.42 \\
\hline$\hat{\alpha}_{15}$ & 1.04931 & 8.06 & 1.11424 & 17.55 & 1.05144 & 9.41 \\
\hline$\hat{\alpha}_{16}$ & 1.05438 & 7.11 & 1.0776 & 15.41 & 1.05206 & 8.19 \\
\hline$\hat{\alpha}_{17}$ & 1.10472 & 7.86 & 1.14869 & 17.12 & 1.10852 & 9.09 \\
\hline$\hat{\alpha}_{18}$ & 1.16242 & 8.45 & 1.21725 & 18.33 & 1.17266 & 9.87 \\
\hline$\hat{\alpha}_{19}$ & 1.22093 & 7.77 & 1.25507 & 16.99 & 1.21677 & 9 \\
\hline$\hat{\alpha}_{20}$ & 1.15979 & 8.99 & 1.29318 & 19.26 & 1.1764 & 10.46 \\
\hline$\hat{\alpha}_{21}$ & 1.37772 & 9.05 & 1.515 & 19.6 & 1.39444 & 10.54 \\
\hline$\hat{\alpha}_{22}$ & 1.55776 & 8.83 & 1.6395 & 19.44 & 1.55993 & 10.33 \\
\hline$\hat{\alpha}_{23}$ & 1.5496 & 8.65 & 1.65198 & 18.85 & 1.56343 & 10.1 \\
\hline$\hat{\alpha}_{24}$ & 1.53571 & 8.89 & 1.61513 & 19.33 & 1.53651 & 10.41 \\
\hline$\hat{\alpha}_{25}$ & 1.77596 & 8.98 & 1.85708 & 19.84 & 1.77433 & 10.5 \\
\hline
\end{tabular}


Table 9. Continued

\begin{tabular}{|c|c|c|c|c|c|c|}
\hline \multirow[b]{2}{*}{ Coefficient } & \multicolumn{2}{|c|}{$1996-2009$} & \multicolumn{2}{|c|}{$1996-2003$} & \multicolumn{2}{|c|}{$1996-2008$} \\
\hline & Estimate & T stat & Estimate & $\mathrm{T}$ stat & Estimate & $\mathrm{T}$ stat \\
\hline$\hat{\alpha}_{26}$ & 1.98367 & 8.98 & 2.05421 & 19.84 & 1.96978 & 10.46 \\
\hline$\hat{\alpha}_{27}$ & 1.91648 & 8.94 & 1.99999 & 19.71 & 1.92248 & 10.46 \\
\hline$\hat{\alpha_{28}}$ & 1.97515 & 8.86 & 2.05081 & 19.54 & 1.96772 & 10.32 \\
\hline$\hat{\alpha}_{29}$ & 2.05311 & 8.96 & 2.14682 & 19.98 & 2.06648 & 10.48 \\
\hline$\hat{\alpha}_{30}$ & 1.96029 & 9.13 & 2.14069 & 20.15 & 1.98993 & 10.66 \\
\hline$\hat{\alpha}_{31}$ & 2.20211 & 9.04 & 2.30098 & 20.16 & 2.21198 & 10.57 \\
\hline$\hat{\alpha}_{32}$ & 2.19385 & 8.94 & 2.30038 & 19.86 & 2.20067 & 10.46 \\
\hline$\hat{\alpha}_{33}$ & 2.25753 & 9.07 & - & - & 2.25844 & 10.61 \\
\hline$\hat{\alpha}_{34}$ & 2.30651 & 9.11 & - & - & 2.30288 & 10.65 \\
\hline$\hat{\alpha}_{35}$ & 2.22761 & 9.06 & - & - & 2.24358 & 10.59 \\
\hline$\hat{\alpha}_{36}$ & 2.26332 & 9.01 & - & - & 2.28033 & 10.52 \\
\hline$\hat{\alpha}_{37}$ & 2.28565 & 9.09 & - & - & 2.2778 & 10.63 \\
\hline$\hat{\alpha}_{38}$ & 2.31307 & 9.14 & - & - & 2.32675 & 10.68 \\
\hline$\hat{\alpha}_{39}$ & 2.32874 & 9.08 & - & - & 2.33781 & 10.62 \\
\hline$\hat{\alpha}_{40}$ & 2.33858 & 8.94 & - & - & 2.3332 & 10.45 \\
\hline$\hat{\alpha}_{41}$ & 2.48442 & 9.11 & - & - & 2.46782 & 10.65 \\
\hline$\hat{\alpha}_{42}$ & 2.4825 & 9.14 & - & - & 2.47822 & 10.68 \\
\hline$\hat{\alpha}_{43}$ & 2.44861 & 9.13 & - & - & 2.42885 & 10.68 \\
\hline$\hat{\alpha}_{44}$ & 2.41217 & 9.08 & - & - & 2.41371 & 10.63 \\
\hline$\hat{\alpha}_{45}$ & 2.56122 & 9.14 & - & - & 2.54368 & 10.69 \\
\hline$\hat{\alpha}_{46}$ & 2.64082 & 9.16 & - & - & 2.64164 & 10.71 \\
\hline$\hat{\alpha}_{47}$ & 2.66495 & 9.14 & - & - & 2.66203 & 10.7 \\
\hline$\hat{\alpha}_{48}$ & 2.68254 & 9.12 & - & - & 2.68008 & 10.66 \\
\hline$\hat{\alpha}_{49}$ & 2.81145 & 9.14 & - & - & 2.80901 & 10.69 \\
\hline$\alpha_{50}$ & 2.98276 & 9.17 & - & - & 2.96145 & 10.73 \\
\hline$\hat{\alpha}_{51}$ & 2.84972 & 9.15 & - & - & 2.82838 & 10.7 \\
\hline$\hat{\alpha}_{52}$ & 2.96522 & 9.14 & - & - & 2.956 & 10.69 \\
\hline$\hat{\alpha}_{53}$ & 2.85257 & 9.16 & - & - & - & - \\
\hline$\hat{\alpha}_{54}$ & 3.02278 & 9.17 & - & - & - & - \\
\hline$\hat{\alpha}_{55}$ & 2.96293 & 9.17 & - & - & - & - \\
\hline$\hat{\gamma}$ & 0.00821 & 13.71 & 0.00928 & 10.46 & 0.00815 & 13.69 \\
\hline$\hat{\omega}$ & 0.00958 & 40.04 & 0.01362 & 29.48 & 0.01014 & 38.25 \\
\hline$\hat{\vartheta}_{2}$ & 1.1668 & 109.17 & 0.90846 & 63.36 & 1.09962 & 106.62 \\
\hline$\hat{\vartheta}_{3}$ & 1.45254 & 80.2 & 1.19659 & 49.21 & 1.40271 & 74.95 \\
\hline$\hat{\vartheta}_{4}$ & 1.71222 & 72.32 & 1.49421 & 48.88 & 1.66785 & 66.63 \\
\hline$\hat{\sigma}_{2}$ & 0.55125 & 131.43 & 0.59487 & 79.96 & 0.54796 & 120.42 \\
\hline$\hat{\sigma_{3}}$ & 0.27964 & 86.2 & 0.30929 & 61.2 & 0.28722 & 80.68 \\
\hline$\hat{\sigma}_{4}$ & 0.18943 & 59.74 & 0.20634 & 46.35 & 0.18856 & 62.46 \\
\hline$\hat{\rho}$ & 0.51334 & 63.49 & 0.54572 & 33.66 & 0.52224 & 61.37 \\
\hline
\end{tabular}


Table 10. Builder's Model estmate over selected time periods.

\begin{tabular}{|c|c|c|c|c|c|c|}
\hline \multirow[b]{2}{*}{ Coefficient } & \multicolumn{2}{|c|}{$1996-2009$} & \multicolumn{2}{|c|}{$1996-2003$} & \multicolumn{2}{|c|}{ 1996-2008 } \\
\hline & Estimate & T stat & Estimate & $\mathrm{T}$ stat & Estimate & $\mathrm{T}$ stat \\
\hline$\hat{\theta}_{1}$ & 18.9504 & 5.14 & 6.54139 & 3.21 & 18.7768 & 5.55 \\
\hline$\hat{\theta}_{2}$ & 51.5232 & 6.01 & 42.3167 & 7.14 & 49.6144 & 6.87 \\
\hline$\hat{\theta}_{3}$ & 37.792 & 6.22 & 27.4228 & 11.44 & 36.5397 & 7.19 \\
\hline$\hat{\theta}_{4}$ & 39.7257 & 6.07 & 30.6971 & 10.47 & 39.5565 & 6.98 \\
\hline$\hat{\theta}_{5}$ & 22.9675 & 6.11 & 11.3205 & 9.2 & 22.2855 & 6.98 \\
\hline$\hat{\theta}_{6}$ & 35.2053 & 6.2 & 24.2672 & 11.5 & 34.2126 & 7.17 \\
\hline$\hat{\theta}_{7}$ & 36.4712 & 6.21 & 25.772 & 11.38 & 35.0501 & 7.2 \\
\hline$\hat{\theta}_{8}$ & 51.3282 & 6.22 & 37.5624 & 11.06 & 50.6889 & 7.2 \\
\hline$\hat{\theta}_{9}$ & 74.1072 & 6.25 & 54.2516 & 12.18 & 76.195 & 7.26 \\
\hline$\hat{\theta}_{10}$ & 65.5811 & 6.25 & 43.2627 & 11.97 & 61.4206 & 7.25 \\
\hline$\hat{\theta}_{11}$ & 77.1784 & 6.21 & 63.6382 & 10.51 & 75.6586 & 7.2 \\
\hline$\hat{\theta}_{12}$ & 29.2054 & 6.01 & 20.9272 & 9.91 & 27.5688 & 6.88 \\
\hline$\hat{\theta}_{13}$ & 38.9776 & 6.17 & 30.5877 & 11.08 & 38.6834 & 7.13 \\
\hline$\hat{\theta}_{14}$ & 60.2137 & 6.24 & 41.4114 & 11.87 & 59.2883 & 7.24 \\
\hline$\hat{\theta}_{15}$ & 96.2797 & 6.2 & - & - & 52.7786 & 6.61 \\
\hline$\hat{\theta}_{16}$ & 58.3052 & 6.2 & 42.518 & 10.83 & 56.2445 & 7.16 \\
\hline$\hat{\theta}_{17}$ & 37.3536 & 6.22 & 28.79 & 11.53 & 37.3925 & 7.19 \\
\hline$\hat{\theta}_{18}$ & 37.2665 & 6.14 & 23.0935 & 10.54 & 35.654 & 7.09 \\
\hline$\hat{\theta}_{19}$ & 45.4616 & 6.21 & 40.2212 & 11.53 & 47.4693 & 7.19 \\
\hline$\hat{\theta}_{20}$ & 38.1906 & 6.17 & 32.9879 & 11.05 & 54.0188 & 7.13 \\
\hline$\hat{\theta}_{21}$ & 44.821 & 5.89 & 30.7749 & 9.59 & 44.4373 & 6.68 \\
\hline$\hat{\theta}_{22}$ & 81.1283 & 6.26 & 59.7162 & 12.32 & 80.3557 & 7.27 \\
\hline$\hat{\alpha}_{2}$ & 0.95139 & 4.59 & 0.97994 & 9.69 & 0.95498 & 5.32 \\
\hline$\hat{\alpha_{3}}$ & 0.99103 & 4.78 & 1.03985 & 10.45 & 1.00201 & 5.57 \\
\hline$\hat{\alpha}_{4}$ & 0.7312 & 3.73 & 0.74296 & 7.74 & 0.75111 & 4.35 \\
\hline$\hat{\alpha_{5}}$ & 0.8116 & 5.01 & 0.87151 & 9.16 & 0.82589 & 5.87 \\
\hline$\hat{\alpha}_{6}$ & 0.95248 & 5 & 0.94333 & 10.8 & 0.95836 & 5.81 \\
\hline$\hat{\alpha}_{7}$ & 0.86708 & 4.99 & 0.88835 & 10.47 & 0.88542 & 5.78 \\
\hline$\hat{\alpha}_{8}$ & 0.84822 & 4.43 & 0.85083 & 8.73 & 0.86098 & 5.14 \\
\hline$\hat{\alpha}_{9}$ & 0.83986 & 4.65 & 0.82827 & 9.86 & 0.85809 & 5.44 \\
\hline$\hat{\alpha}_{10}$ & 0.82253 & 5.94 & 0.85865 & 12.16 & 0.83475 & 6.96 \\
\hline$\hat{\alpha}_{11}$ & 0.83732 & 4.27 & 0.82706 & 8.83 & 0.85551 & 4.93 \\
\hline$\hat{\alpha}_{12}$ & 0.90912 & 3.97 & 0.86057 & 7.86 & 0.92308 & 4.66 \\
\hline$\hat{\alpha}_{13}$ & 0.96641 & 4.94 & 0.93825 & 9.97 & 0.97604 & 5.68 \\
\hline$\hat{\alpha}_{14}$ & 0.8793 & 5.94 & 0.90544 & 11.97 & 0.89432 & 6.95 \\
\hline$\hat{\alpha}_{15}$ & 1.08107 & 5.38 & 1.06596 & 11.46 & 1.08874 & 6.3 \\
\hline$\hat{\alpha}_{16}$ & 1.06128 & 4.85 & 1.03543 & 10.05 & 1.06836 & 5.7 \\
\hline$\hat{\alpha}_{17}$ & 1.17468 & 5.72 & 1.13803 & 12.11 & 1.18416 & 6.66 \\
\hline$\hat{\alpha}_{18}$ & 1.23711 & 5.87 & 1.19014 & 12.49 & 1.25593 & 6.83 \\
\hline$\hat{\alpha}_{19}$ & 1.38538 & 5.45 & 1.32108 & 11.49 & 1.38288 & 6.32 \\
\hline$\hat{\alpha}_{20}$ & 1.35506 & 6.15 & 1.43629 & 12.9 & 1.36738 & 7.17 \\
\hline$\hat{\alpha}_{21}$ & 1.82033 & 6.2 & 1.86218 & 13.25 & 1.80975 & 7.23 \\
\hline$\hat{\alpha}_{22}$ & 2.00595 & 6.04 & 1.98121 & 13.1 & 1.99718 & 7.02 \\
\hline$\hat{\alpha}_{23}$ & 2.0415 & 6.02 & 2.06597 & 13.02 & 2.0506 & 7.01 \\
\hline$\hat{\alpha}_{24}$ & 2.052 & 6.1 & 2.01282 & 13.11 & 2.04297 & 7.1 \\
\hline$\hat{\alpha}_{25}$ & 2.38189 & 6.22 & 2.34719 & 13.58 & 2.36248 & 7.24 \\
\hline$\hat{\alpha}_{26}$ & 2.76026 & 6.21 & 2.72731 & 13.59 & 2.71551 & 7.23 \\
\hline$\hat{\alpha}_{27}$ & 2.75262 & 6.2 & 2.71339 & 13.55 & 2.73398 & 7.22 \\
\hline
\end{tabular}


Table 10. Continued

\begin{tabular}{|c|c|c|c|c|c|c|}
\hline \multirow[b]{2}{*}{ Coefficient } & \multicolumn{2}{|c|}{ 1996-2009 } & \multicolumn{2}{|c|}{$1996-2003$} & \multicolumn{2}{|c|}{$1996-2008$} \\
\hline & Estimate & T stat & Estimate & T stat & Estimate & T stat \\
\hline$\hat{\alpha}_{28}$ & 2.77131 & 6.13 & 2.77153 & 13.38 & 2.74748 & 7.13 \\
\hline$\hat{\alpha}_{29}$ & 2.92292 & 6.2 & 2.90953 & 13.62 & 2.91331 & 7.22 \\
\hline$\hat{\alpha}_{30}$ & 2.93856 & 6.28 & 2.9939 & 13.69 & 2.91188 & 7.31 \\
\hline$\hat{\alpha}_{31}$ & 3.23666 & 6.24 & 3.22505 & 13.65 & 3.21179 & 7.27 \\
\hline$\hat{\alpha}_{32}$ & 3.26326 & 6.21 & 3.28622 & 13.59 & 3.23435 & 7.23 \\
\hline$\hat{\alpha}_{33}$ & 3.35212 & 6.27 & - & - & 3.31537 & 7.3 \\
\hline$\hat{\alpha}_{34}$ & 3.38355 & 6.28 & - & - & 3.3352 & 7.32 \\
\hline$\hat{\alpha}_{35}$ & 3.2087 & 6.26 & - & - & 3.20256 & 7.3 \\
\hline$\hat{\alpha}_{36}$ & 3.27093 & 6.23 & - & - & 3.27335 & 7.25 \\
\hline$\hat{\alpha}_{37}$ & 3.29137 & 6.27 & - & - & 3.26951 & 7.31 \\
\hline$\hat{\alpha}_{38}$ & 3.37566 & 6.28 & - & - & 3.37289 & 7.32 \\
\hline$\hat{\alpha}_{39}$ & 3.31833 & 6.26 & - & - & 3.30773 & 7.3 \\
\hline$\hat{\alpha}_{40}$ & 3.34384 & 6.21 & - & - & 3.30449 & 7.24 \\
\hline$\hat{\alpha}_{41}$ & 3.63297 & 6.27 & - & - & 3.58544 & 7.31 \\
\hline$\hat{\alpha}_{42}$ & 3.48696 & 6.28 & - & - & 3.46523 & 7.33 \\
\hline$\hat{\alpha}_{43}$ & 3.51955 & 6.28 & - & - & 3.49224 & 7.32 \\
\hline$\hat{\alpha}_{44}$ & 3.3684 & 6.25 & - & - & 3.35519 & 7.29 \\
\hline$\hat{\alpha}_{45}$ & 3.65136 & 6.28 & - & - & 3.61947 & 7.32 \\
\hline$\hat{\alpha}_{46}$ & 3.76422 & 6.29 & - & - & 3.73952 & 7.33 \\
\hline$\hat{\alpha}_{47}$ & 3.7964 & 6.28 & - & - & 3.76926 & 7.33 \\
\hline$\hat{\alpha}_{48}$ & 3.87238 & 6.27 & - & - & 3.85314 & 7.31 \\
\hline$\hat{\alpha}_{49}$ & 3.98489 & 6.29 & - & - & 3.96809 & 7.33 \\
\hline$\alpha_{50}$ & 4.20267 & 6.29 & - & - & 4.16664 & 7.34 \\
\hline$\hat{\alpha}_{51}$ & 4.12712 & 6.28 & - & - & 4.08914 & 7.32 \\
\hline$\hat{\alpha}_{52}$ & 4.18693 & 6.28 & - & - & 4.10956 & 7.32 \\
\hline$\hat{\alpha}_{53}$ & 4.1375 & 6.29 & - & - & - & - \\
\hline$\hat{\alpha}_{54}$ & 4.3602 & 6.3 & - & - & - & - \\
\hline$\hat{\alpha}_{55}$ & 4.4187 & 6.3 & - & - & - & - \\
\hline$\hat{\gamma}$ & 0.01035 & 14.87 & 0.01271 & 10.81 & 0.01 & 14.45 \\
\hline$\hat{\omega}$ & 0.01202 & 37.52 & 0.01869 & 26.34 & 0.01233 & 35.84 \\
\hline$\hat{\vartheta}_{2}$ & 1.11502 & 95.13 & 0.85087 & 49.33 & 1.06155 & 91.11 \\
\hline$\hat{\vartheta}_{3}$ & 1.42347 & 72.63 & 1.12454 & 41.79 & 1.41089 & 70.18 \\
\hline$\hat{\vartheta}_{4}$ & 1.58045 & 64.35 & 1.3149 & 40.44 & 1.59713 & 62.24 \\
\hline$\hat{\sigma}_{2}$ & 0.56898 & 120.51 & 0.60896 & 64.85 & 0.59141 & 109.21 \\
\hline$\hat{\sigma_{3}}$ & 0.30705 & 72.27 & 0.34388 & 45.43 & 0.32543 & 67.53 \\
\hline$\hat{\sigma_{4}}$ & 0.20825 & 55.63 & 0.23093 & 38.31 & 0.21331 & 56.84 \\
\hline$\hat{\rho}$ & 0.10284 & 6.12 & -0.09809 & -2.01 & 0.08523 & 4.76 \\
\hline$\hat{\delta}$ & 0.02351 & 46.04 & 0.01281 & 15.88 & 0.02494 & 46.12 \\
\hline$\hat{\tau}_{2}$ & 1.5368 & 78.92 & 1.44034 & 58.67 & 1.60901 & 80.03 \\
\hline$\hat{\tau}_{3}$ & 1.5062 & 57.6 & 1.3037 & 43.2 & 1.55714 & 55.62 \\
\hline$\hat{\varphi}_{2}$ & 1.38799 & 89.44 & 1.37268 & 80.35 & 1.36278 & 91.21 \\
\hline$\hat{\varphi}_{3}$ & 1.54054 & 30.65 & 1.58115 & 35.99 & 1.55477 & 33.45 \\
\hline$\hat{\varphi}_{2}$ & 1.24776 & 137.27 & 1.18751 & 100.68 & 1.21771 & 134.86 \\
\hline$\hat{\eta}_{2}$ & 1.23058 & 133.3 & 1.0808 & 90.13 & 1.20633 & 126.45 \\
\hline
\end{tabular}




\section{References}

Davis, M., and M. Palumbo. 2008. "The Price of Residential Land in Large US Cities." Journal of Urban Economics 63: 352-384. DOI: https://doi.org/10.1016/j.jue.2007. 02.003 .

De Haan, J., and W.E. Diewert. 2013. "Hedonic Regression Methods." In Handbook on Residential Property Prices Indices, edited by J. De Hann and W.E. Diewert. (pp. 49-64). Luxembourg: Publication Office of the European Union, Eurostat. Available at: https://ec.europa.eu/eurostat/documents/3859598/5925925/KS-RA-12-022-EN.PDF (accessed November 2019).

Diewert, W.E. 2009. "Basic Index Number Theory." In Consumer Price Index Manual: Theory and Practice, edited by P. Hill. (pp. 263-268). Geneva: International Labour Organization (ILO). Available at: https://www.ilo.org/wcmsp5/groups/public/--dgreports/--stat/documents/presentation/wcms_331153.pdf (accessed November 2019).

Diewert, W.E. 2013. "Decomposing an RPPI into Land and Structure Components." In Handbook on Residential Property Prices Indices, edited by J. De Hann and W.E. Diewert. (pp. 82-99). Luxembourg: Publication Office of the European Union, Eurostat. Available at: https://ec.europa.eu/eurostat/documents/3859598/5925925/KSRA-12-022-EN.PDF (accessed November 2019).

Diewert, W.E., and C. Shimizu. 2016. "Hedonic Regression Models for Tokyo Condominium Sales." Regional Science and Urban Economics 60: 300-315. DOI: https://doi.org/10.1016/j.regsciurbeco.2016.08.002.

Diewert, W.E., and C. Shimizu. 2017. "Alternative Approaches to Commercial Property Price Indexes for Tokyo." Review of Income and Wealth 63(3): 492-519. DOI: http:// doi.org/10.1111/roiw.12229.

Prasad, N., and A. Richards. 2006. "Measuring Housing Price Growth: Using Stratification to Improve Median-Based Measures.” In Research Discussion Paper 2006-04, Reserve Bank of Australia. Available at: https://www.rba.gov.au/publications/rdp/2006/pdf/rdp 2006-04.pdf (accessed November 2019)

Read-Hobman, T. 2015. "Evolution of Housing in Canada, 1957 to 2014." In Canadian Megatrends. Ottawa: Statistics Canada, Catalogue no. 11-630-X. Available at: https:// www150.statcan.gc.ca/n1/pub/11-630-x/11-630-x2015007-eng.pdf (accessed November 2019).

Received November 2019

Revised July 2020

Accepted August 2020 